\title{
Seasonal Climate of the Tropical Atlantic Sector in the NCAR Community Climate System Model 3: Error Structure and Probable Causes of Errors
}

\author{
Ching-Yee Chang, James A. Carton, Semyon A. Grodsky, and Sumant Nigam \\ Department of Atmospheric and Oceanic Science, and Earth System Science Interdisciplinary Center, University of Maryland, \\ College Park, College Park, Maryland
}

(Manuscript received 23 January 2006, in final form 20 June 2006)

\begin{abstract}
The Community Climate System Model version 3 (CCSM3) has a dipolelike pattern with a cold bias in the northern Tropics and a warm bias in the southeastern Tropics, which is reminiscent of the observed pattern of climate variability in boreal spring. Along the equator, in contrast, in boreal spring CCSM3 exhibits striking westerly winds with easterly winds in the upper troposphere, in turn reminiscent of the observed pattern of climate variability in boreal summer. The westerly winds cause a deepening of the eastern thermocline that keeps the east warm despite enhanced coastal upwelling. Thus, the bias in the seasonal cycle of the coupled model appears to project at least partially onto the spatial patterns of natural climate variability in this sector.

Information about the origin of the bias in CCSM3 is deduced from a comparison of CCSM3 with a simulation using specified historical SST to force the Community Atmospheric Model version 3 (CAM3). The patterns of bias in CAM3 resemble those apparent in CCSM3, including the appearance of substantially intensified subtropical bands of sea level pressure (SLP), indicating that the problem may be traced to difficulties in the atmospheric component model. Positive SLP bias also appears in the western tropical region, which may be related to deficient Amazonian precipitation. The positive SLP bias seems to be the cause of the anomalous westerly trade winds in boreal spring, and those in turn appear to be responsible for the anomalous deepening of the thermocline in the southeastern Tropics.
\end{abstract}

\section{Introduction}

Although the climate of the tropical Atlantic Ocean is simple in that it is strongly seasonal, this strong seasonality has proven remarkably difficult to simulate (Davey et al. 2002; Deser et al. 2006). In the intercomparison study, Davey et al. (2002) show that for most of the non-flux-corrected coupled general circulation models (GCMs), the simulated zonal equatorial SST gradient is opposite to its observed direction, and the zonal equatorial wind stress is too weak. This model deficiency is important because errors in the simulation of seasonal climate are likely to cause similar errors in the representation of year-to-year variability. Recently, a remarkable set of experiments has become available for comparison with the Community Climate System

Corresponding author address: James A. Carton, Department of Atmospheric and Oceanic Science/Earth System Science Interdisciplinary Center, University of Maryland, College Park, College Park, MD 20742.

E-mail: carton@atmos.umd.edu

DOI: 10.1175/JCLI4047.1

(C) 2007 American Meteorological Society
Model version 3 (CCSM3) coupled model. In this paper we examine CCSM3 to describe the seasonal climate of the Atlantic sector in this state-of-the-art model. Our goal is to identify differences from the observed climate in an effort to develop hypotheses regarding the causes of these errors.

The origins of the seasonal cycle in this sector are linked to the proximity of continental convective zones and the geometry of the eastern boundary (Mitchell and Wallace 1992; Xie 1994; Chang and Philander 1994; Nigam and Chao 1996; Li and Philander 1996). The tropical Atlantic is flanked in the east by the West African continent, which extends to $10^{\circ} \mathrm{W}$ north of $3^{\circ} \mathrm{N}$ and supports a significant boreal summer monsoon. Convection over land is affected by the presence of an inland plateau, which reaches heights of some $1 \mathrm{~km}$. The onset of the boreal summer monsoon in May following the northward shift of solar declination is associated with the intensification of southeasterly trade winds along and south of the equator, a northward shift of the intertropical convergence zone (ITCZ), and the associated intense convection. The initiation of the 
West African monsoon, together with the enhanced southeasterly trade winds, cools SST along the equator (the cold tongue) and the African coast. The cold tongue appears initially along the equator $\left(3^{\circ} \mathrm{S}-0^{\circ}\right)$ between $20^{\circ}$ and $10^{\circ} \mathrm{W}$ in late May and spreads southeastward to $10^{\circ} \mathrm{S}$ in the following season as a result of intensifying coastal upwelling, the southeastward propagating coastal Kelvin waves that shallow the thermocline, the northwestward advection of cool surface water along the coast, and the reduction in solar isolation resulting from the shading by stratus clouds ( $\mathrm{Yu}$ and Mechoso 1999). At the same time, the intensifying winds cause a tremendous increase in mixing and entrainment, bringing this cool water into the mixed layer and amplifying the effects of surface latent heat loss (Foltz et al. 2003). The SST-induced anomalous pressure gradient at the western flank of the cold tongue enhances the easterly wind there. The enhanced wind produces extra cooling through equatorial upwelling to the west of the original cool SST anomaly, thus shifting the cold anomaly westward as envisioned in the "westward SST expansion" hypothesis (Nigam and Chao 1996; Okumura and Xie 2004). South of the equator the continent lies east of $10^{\circ} \mathrm{E}$ and in that hemisphere the boreal winter monsoon remains primarily confined to the continent (Xie and Carton 2004).

In boreal late fall in response to increasing solar insolation in the Southern Hemisphere and weakening equatorial winds, the equatorial thermocline becomes less steeply sloped. In the east the deepened thermocline reduces the temperature drop across the base of the oceanic mixed layer. The reduction in the temperature drop reduces the effectiveness of entrainmentinduced cooling. In the southeast surface insolation reaches its maximum in January-February while latent heat loss remains close to its annual average. As a result, the heat content of the oceanic mixed layer increases throughout this season. In the Northern Hemisphere the increase in latent heat loss resulting from strengthening trade winds is partly compensated for by an increase in surface insolation resulting from reduced cloudiness. The result of these changes in mixed layer heating in December-February (DJF) is that by March-April SSTs are uniformly warm throughout the tropical sector. Thus, March-May (MAM) and JuneAugust (JJA) represent the warm and cool extremes of the seasonal cycle in this sector.

Superimposed on this seasonal cycle the tropical Atlantic supports significant year-to-year variability of at least two types (Xie and Carton 2004). During the cool boreal summer season the zonal trade winds along the equator relax in some years. This relaxation of the zonal trade winds, the corresponding southward shift of the ITCZ, and the weakening of the West African monsoon all occur in concert with a warming of the oceanic cold tongue and a deepening of the eastern equatorial thermocline. The conglomeration of events occurring during the Atlantic El Niño is reminiscent of El Niño in the Pacific, but is weaker in magnitude, more linked to boreal summer, and more frequent. The warm water in the equatorial area resulting from Atlantic El Niño sometimes can flow southward along the Benguela coast, resulting in a warming event in that region, which is one of the causes of the development of the "Benguela Niño" (Hagen et al. 2001). In contrast to the cool season Atlantic El Niño, in the warm season of MAM the latitudinal position of the ITCZ is sensitive to small changes in the interhemispheric gradient of SST resulting from the uniformity of SST (Chiang et al. 2002; Kushnir et al. 2002; Xie and Carton 2004). During this sensitive season a southward gradient of anomalous SST induced either by local air-sea interaction or by remote influence from the Pacific can push the ITCZ southward, strengthening the northeast trade winds along the equator, weakening the southeast trade winds, and shifting convection southward as well (Xie and Carton 2004). The presence of these natural sources of year-to-year variability are interesting because of the possibility that similar mechanisms may cause systematic errors in the seasonal climate of coupled models. The physics of this year-to-year variability has, incidentally, also been applied to understand the cause of tropical Atlantic paleoclimate changes (Chiang et al. 2003).

The Community Climate System Model (CCSM) project has developed since the 1990s to provide a tool for examining climate variability (Boville and Gent 1998). SSTs in the original version Climate System Model version 1 (CSM1) showed errors of $1^{\circ}-3^{\circ} \mathrm{C}$ in the southeastern tropical Atlantic, but with near-climatological SSTs in the north. Like many of the coupled models described in Davey et al. (2002), CSM1 had similar SST errors in the tropical Pacific. The latest version of the CCSM, version 3 (CCSM3), is designed to address a number of deficiencies in the original model (Collins et al. 2006a) and some errors are substantially reduced, particularly in the representation of ENSO variability. However, examination of the mean climate of CCSM3 by Deser et al. (2006) highlights some persistent problems in the tropical Atlantic. These include cold tongue SSTs that are $3^{\circ} \mathrm{C}$ too warm $\left(26^{\circ} \mathrm{C}\right)$, Caribbean Sea SSTs that are $1^{\circ} \mathrm{C}$ too cold, a southward displacement of the ITCZ notably in boreal winter, and an absence of year-to-year variability along the equator (the Atlantic El Niño). Deser et al. (2006) suggest that these problems may be traced back to the 
poor simulation of the West African monsoon by the atmosphere model [known as the Community Atmosphere Model version 3 (CAM3)] even when forced by observed SST.

The problem of tropical bias in CCSM3 has also been discussed by Large and Danabasoglu (2006) in the context of the ocean's influence on the coupled model. Although primarily focused on the mean climate and the seasonal cycle in the tropical Pacific, Large and Danabasoglu examine an interesting experiment in which ocean temperature and salinity in the southeastern boundary regions of an enhanced resolution (T85) version of CCSM3 are returned to their observed climatological values, but for which the model is otherwise unconstrained. The result of this experiment was a reduction of eastern ocean temperatures, closer to those observed. A subsequent ocean-only experiment led the authors to suggest that the cause of the warm bias in the southeastern tropical oceans could be traced back to inadequate coastal upwelling close to the coast; that is, they suggested the cause was primarily contained in the ocean model.

DeWitt (2005), using the ECHAM4.5 atmospheric GCM and the Modular Ocean Model version 3 (MOM3) ocean GCM, shows in the ocean-only/coupled model study that the weak zonal wind stress along the equator may be the cause of the appearance of an incorrect zonal equatorial SST gradient. In another ocean-only/coupled model study, Hazeleger and Haarsma (2005) show that increasing the efficiency of wind-driven vertical mixing results in a deeper thermocline depth and higher SST, thus offering another explanation for the SST bias. Yu and Mechoso (1999) suggest that the source of the model bias lies in the improper representation of low-level clouds over the eastern tropical oceans. In this study we revisit the problem of tropical bias in the seasonal cycle of the CCSM3 coupled model examining the tropical Atlantic sector and consider the coupled changes that occur in the atmosphere and ocean as well as the relationship to changes in the subtropics. This broad examination identifies both tropical and subtropical processes that appear to be contributing simultaneously to the errors in SST as well as to related errors in winds and precipitation.

\section{Model and data}

The CCSM3 data used in this study are the output data of the "20th Century Climate in Coupled Models" project conducted for the Intergovernmental Panel on Climate Change. The output data are archived at the Program for Climate Model Diagnosis and Intercomparison Web site. Our study uses the case b30.030a
(20C3M run 1) This simulation was initiated on 1 January 1870 and integrated until 31 December 1999. This is a simulation forced by historical ozone, solar, volcanic, and greenhouse gases, and sulfur dioxide/trioxide forcings with carbon distribution linearly scaled to population. Our analysis focuses on data for the final 50-yr period beginning January 1950. A sensitivity examination has been carried out to ensure that the climatology of this particular case is similar to that of other cases and to that of the ensemble. The data are simulated based on the configuration of CCSM3 with atmosphere and land models [CAM3 and Community Land Model version 3 (CLM3)] and ocean and sea ice models [Parallel Ocean Program (POP1.4.3) and the Community Sea Ice Model version 5 (CSIM5)]. These models are connected to a flux coupler individually and can only exchange data with the coupler. Fluxes exchanged among component models were not adjusted during this simulation. The atmosphere model (CAM3) is based on the Eulerian spectral dynamical core with triangular spectral truncation at 85 wavenumber (T85; approximately $1.41^{\circ}$ zonal resolution) and 26 levels (Collins et al. 2006a,b). In CAM3, a prognostic cloud parameterization replaces the diagnostic parameterization used in previous versions. Different evolution equations are applied for liquid and ice condensate. The new radiative parameterizations allow shortwave and longwave radiation to interact with cloud geometry and water vapor. A prescribed aerosol climatology is used in calculating the aerosol's radiative effects on shortwave fluxes and heating rates. This is an important consideration in the northern tropical Atlantic where Saharan dust may alter the surface radiative flux by 30 $\mathrm{W} \mathrm{m}^{-2}$ (Carlson and Benjamin 1980). The calculation of the thermodynamic tendencies has been reformulated relative to earlier versions of CCSM to ensure conservation of energy.

We also examine a CAM3 Atmospheric Model Intercomparison Project (AMIP) run using the enhanced version of CAM3 (T85), with prescribed SST for the period of 1950 through 2001. The SST datasets were constructed by concatenating global Hadley Centre Sea Ice and Sea Surface Temperature dataset (HadISST) (Rayner et al. 2003) for the years of 1950-81 with the Reynolds et al. (2002) SST dataset for years after 1981.

The ocean model is based on POP1.4.3 primitive equation numerics (see, e.g., Danabasoglu et al. 2006). The model grid has a displaced pole in order to resolve the Arctic Ocean and has a nominal horizontal resolution of $1^{\circ} \times 1^{\circ}$ in the Tropics, with 40 levels (10-m resolution near surface). Vertical mixing of heat and momentum uses a modified K-profile parameterization, while horizontal mixing is parameterized as a dif- 
fusive process with constant diffusion coefficients. Surface boundary conditions of heat, freshwater, and momentum are provided by the flux coupler. Solar radiation is allowed to penetrate into the ocean with an absorption profile that varies spatially and monthly based on satellite-based estimates of chlorophyll concentration. An additional modification is included to simulate the effect on mixed layer heating of diurnal variations. The initial condition of the ocean model is the climatological January mean potential temperature and salinity, but zero velocity (Danabasoglu et al. 2006).

To evaluate the performance of CCSM3 and CAM3 we compare the results to observation-based climatological analyses of atmospheric and ocean winds/ currents, and precipitation, atmospheric vertical motion, ocean temperature, and several surface variables [surface winds, SST, sea level pressure (SLP), and net shortwave]. In choosing observation sets we require a minimum of $10 \mathrm{yr}$ of data in order to estimate a stable seasonal cycle. A number of variables are available based on satellite measurements. Our SST observation dataset has the same combination of SST datasets that are used for the CAM3 AMIP run (Rayner et al. 2003; Reynolds et al. 2002). Observed surface winds are available also in a $1^{\circ} \times 1^{\circ}$ grid from the Special Sensor Microwave Imager for the 13-yr period of 1988-2000 (Atlas et al. 1996) and are patched with the National Aeronautics and Space Administration (NASA) Quick Scatterometer (QuikSCAT) winds (Graf et al. 1998), which are available from mid-1999 to 2005. These nominally 10 -m winds have an uncertainty of $\pm 2 \mathrm{~ms}^{-1}$ in our sector of interest.

For net shortwave radiation we rely on the University of Maryland (UMD) Shortwave Radiation Budget (SRB) model D1 monthly analysis of Pinker et al. (2001), which is available on a $2.5^{\circ} \times 2.5^{\circ}$ grid for the 12-yr period of 1983-2004. Precipitation is provided by the Global Precipitation Climatology Project Version 2 monthly precipitation data on a $2.5^{\circ} \times 2.5^{\circ}$ grid for the 27-yr period 1979-2005 (Adler et al. 2003). The estimated random error ranges between $10 \%$ and $30 \%$ in regions where precipitation amounts exceed $3 \mathrm{~mm}$ day $^{-1}$. In the Atlantic sector, Adler et al. (2003) suggest that the maximum precipitation in the ITCZ may be underestimated.

The remaining variables cannot be estimated from satellite datasets. For sea level pressure and vertical motion, we rely on the monthly mean of the National Centers for Environmental Prediction-National Center for Atmospheric Research (NCEP-NCAR) daily reanalysis of Kalnay et al. (1996), available for the full 50 -yr period of interest on a $2.5^{\circ} \times 2.5^{\circ}$ grid. Ocean currents and temperature are provided by the Simple
Ocean Data Assimilation (V1.4.2) ocean reanalysis of Carton and Giese (2006, manuscript submitted to Mon. Wea. Rev.), which is available for a period of $44 \mathrm{yr}$ (1958-2001) on a $0.5^{\circ} \times 0.5^{\circ}$ grid at 40 vertical levels.

As indicated in the introduction, the climate of the tropical Atlantic is characterized by a cool season (JJA) and a warm season (MAM). Thus, we focus our examination of CCSM3 and CAM3 on their performance in these two extreme seasons. The seasonal averages are computed by combining the monthly averages for the full records. Later it will be of interest to carry out a spectral analysis. This is carried out by Fourier decomposition of the monthly averages.

\section{Results}

The presentations of the results are organized in the following way. In the first part of this section we address seasonal errors in atmospheric circulation and SST, beginning with mean and seasonal SST. We then examine tropical surface wind fields, which are additionally affected by the subtropical distribution of SLP. Errors in winds and SLP are also related to errors in vertical motion and diabatic heating, and so we present the seasonal distribution of precipitation. In the second part of this section we address processes implicated in the development of seasonal errors in SST variability, including radiative and thermodynamic fluxes, and entrainment/mixing in the ocean.

We begin by examining the spatial pattern of SST in the cool (JJA) and warm (MAM) seasons. In CCSM3 SST during JJA is too warm by $1^{\circ}-3^{\circ} \mathrm{C}$ in the southeast, with the zone of anomalous temperature extending westward from the coast of Africa and also along the equator (Fig. 1). In the northern Tropics SST is too cool throughout the year by $1^{\circ}-2^{\circ} \mathrm{C}$. Along the equator in JJA SST is $1^{\circ} \mathrm{C}$ too cool in the west and too warm in the east by up to $3^{\circ} \mathrm{C}$ so that the zonal gradient of temperature is positive, in conflict with observations. During MAM the anomalously warm SST in the southeast persists, but is confined to a narrower zone within $10^{\circ}$ of the southeastern boundary. The contrasting cool and warm biases in SST in the Northern and Southern Hemispheres, which induce a southward shift of the trade wind systems and northward intensification in the gradient of SLP, are reminiscent of one phase of the interhemispheric mode. Along the equator the cool bias in the west and the warm bias in the east contribute to a westward bias in the CCSM3 SLP gradient.

A climatology of SST along the equator shows that the cold tongue does not appear in CCSM3, while anomalies propagate eastward. The eastward progression of warm anomaly in the first half of the year has a higher speed than the cold anomaly in the second half 
a) Obs

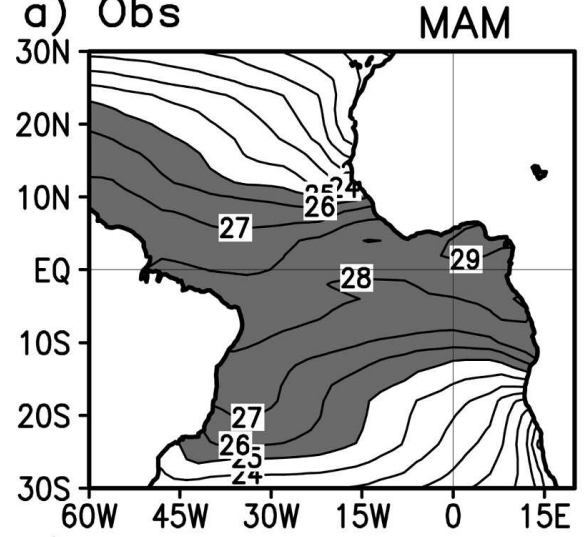

b) $\operatorname{CCSM} 3 \quad M A M$

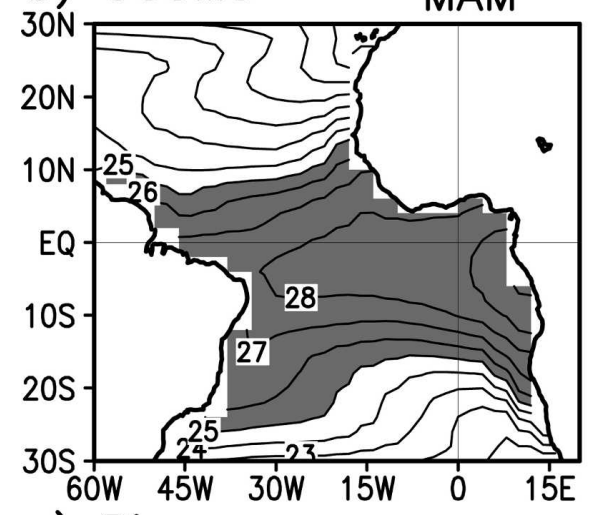

c) Bias

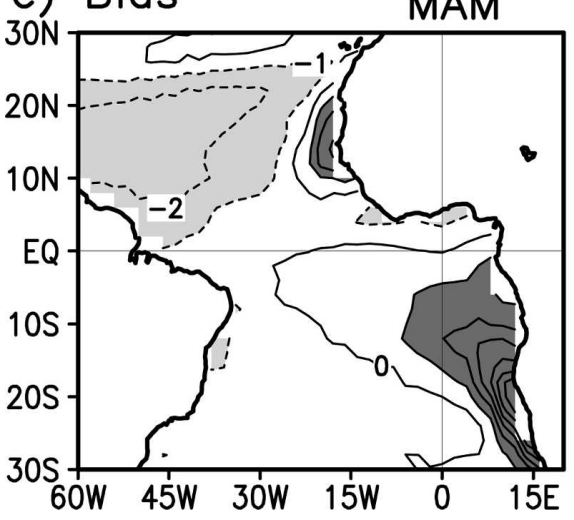

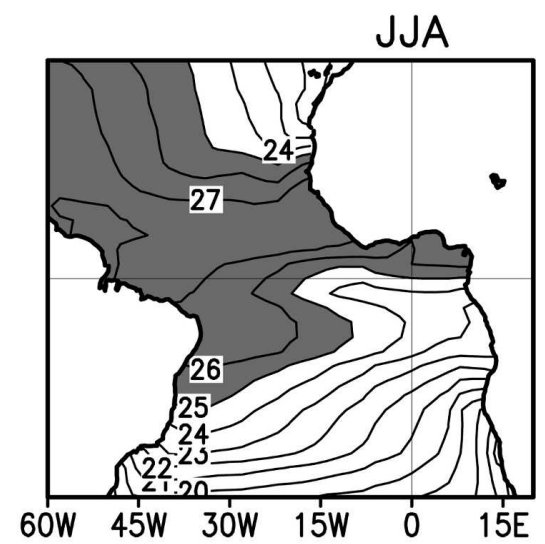
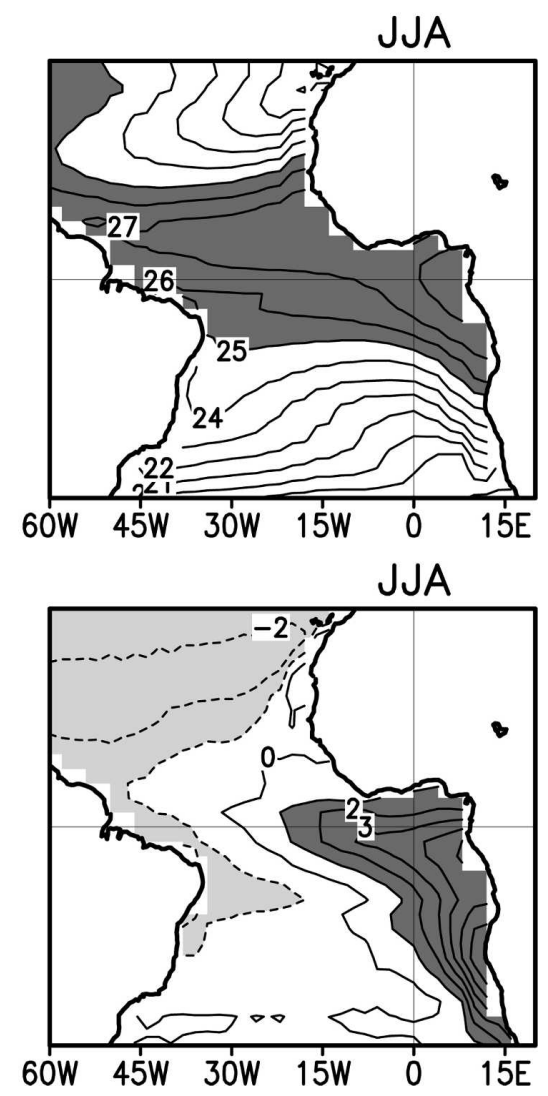

FIG. 1. Seasonal SST: (a) observed, (b) CCSM3, and (c) SST bias (CCSM3 minus observed). Units: ${ }^{\circ} \mathrm{C}$.

of the year (Fig. 2a). To understand the nature of the seasonal cycle of SST along the equator we decompose monthly CCSM3 SST into its annual and semiannual harmonics (Fig. 2b). The annual harmonic is similar in magnitude to the observations, but differs in fundamental ways. The CCSM3 annual harmonic appears first west of $30^{\circ} \mathrm{W}$ and progresses eastward, reflecting the eastward progression noted in Fig. 2a. This result is in conflict with the observed annual harmonic, which appears first at the coast of Africa and progresses west- ward. The direction of progression of the annual cycle is projected by the direction of the anomaly progression in SST climatology, which is connected to the geographic location of the source (Africa, in the case of the observation) and to the role of the trade winds in controlling mixed layer properties, as discussed in the introduction. In CCSM3 westerly equatorial winds prevail in MAM (Fig. 2c), thus inverting the processes leading to the observed westward development of seasonal winds and SST, but which in the model lead to the 
a)Climatological SST
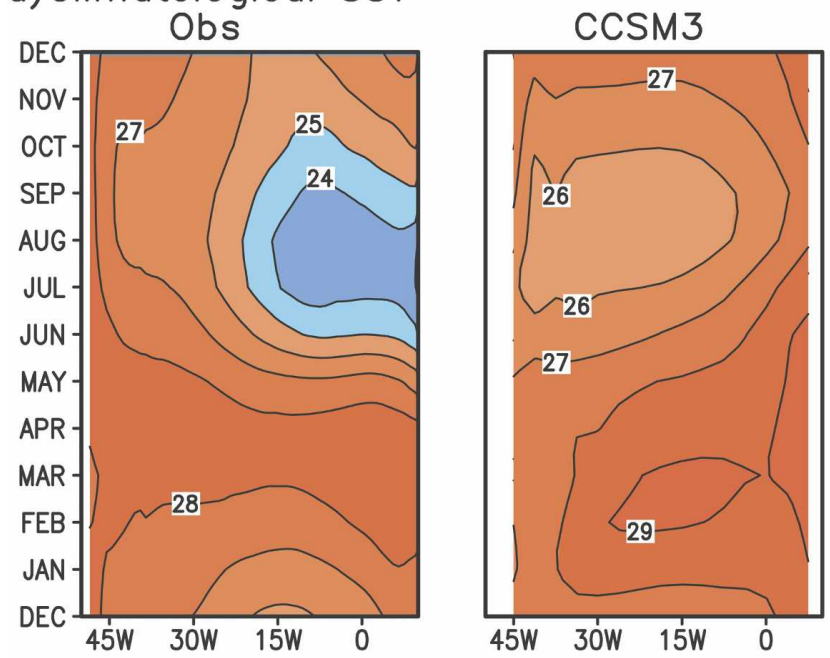

b)Annual and Semiannual cycle
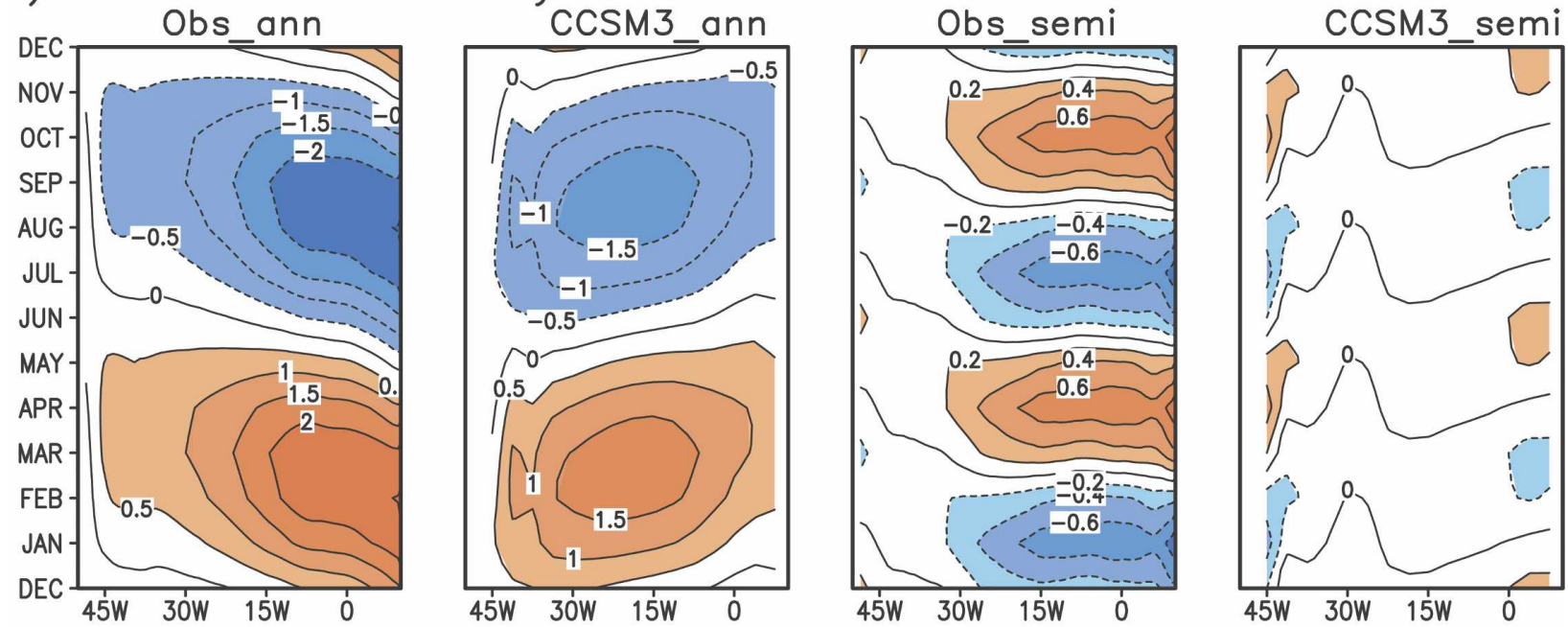

c) Climatological equatorial winds

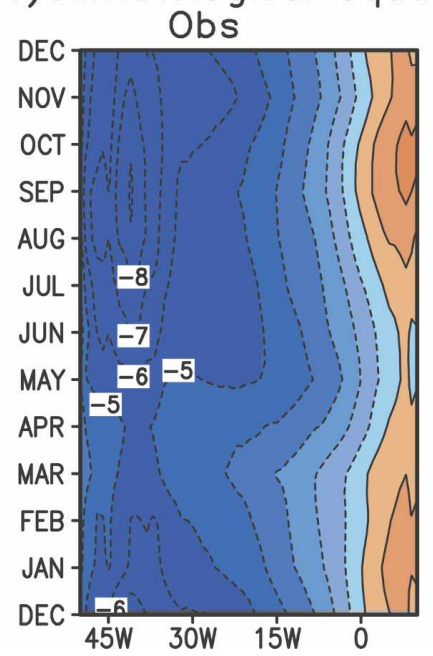

\section{$\operatorname{cCSM} 3$}
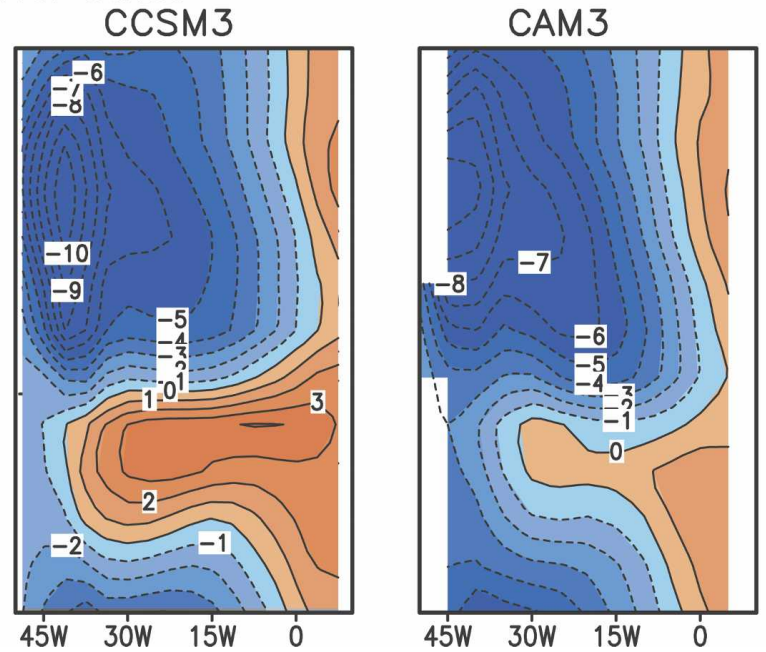

FIG. 2. Observed and CCSM3 equatorial SST and zonal winds (averaged from $4^{\circ} \mathrm{S}$ to $0^{\circ}$ ) vs longitude for (a) SST and (b) annual and semiannual harmonics of SST $\left({ }^{\circ} \mathrm{C}\right)$, and (c) observed, CCSM3, and CAM3 zonal winds. 
eastward development of these variables. Another difference between the model and observation is the fact that CCSM3 has stronger summertime cooling in the western basin, whereas the observation shows stronger cooling in the eastern basin. This difference may result from the thermodynamic effect of the stronger winds in the west during JJA in CCSM3 than in the observation, while the effects of entrainment are weaker in the east because the thermocline is too deep (Fig. 3c).

The observed seasonal cycle of SST also has a significant semiannual cycle (Fig. 2b), with coldest SSTs in January and July. The most important factor governing the semiannual cycle is a response to the semiannually changing insolation. However, at least two additional factors contribute to this harmonic. One results from the semiannual increase in insolation over equatorial Africa (in March and September) increasing air temperature and lowering SLP. Lower SLP results in anomalous southerly winds that lead the cooling of the SST through coastal upwelling a month or two later. The second factor is the suddenness of the entrainment of cool subthermocline water into the observed mixed layer in June-July, which thus projects onto the semiannual harmonic with peaks in June-July and December-January. In comparison to observations, the CCSM3 thermocline (Fig. 3c) in the eastern basin is too deep by 20-40 m throughout the year. This error increases the thermal inertia of the mixed layer and prevents the seasonal entrainment of cool subthermocline water. As a result the mechanisms giving rise to the observed semiannual harmonic in SST do not contribute to CCSM3.

The persistent anomalous meridional dipole pattern in CCSM3 SST occurs in conjunction with a crossequatorial pressure gradient, shifting the latitude of the trade wind systems southward by $5^{\circ}-10^{\circ}$ in the warm season (Fig. 4). This southward shift causes the northeast trade winds to cross south of the equator, giving a strong $3 \mathrm{~m} \mathrm{~s}^{-1}$ northerly wind anomaly along the equator. At the same time the southeast trade winds become stronger between $25^{\circ}$ and $5^{\circ} \mathrm{S}$, resulting in intensified convergence in the displaced ITCZ and a strongerthan-observed Atlantic Hadley circulation (the vertical branches of this circulation are discussed below). In the east, the strengthened southeast trade winds extend to the coasts of southern Angola and Namibia where they act to intensify the coastal upwelling that normally prevails along these coasts (Xie and Carton 2004). As noted below, however, the impact of coastal upwelling on SST is mitigated by the anomalously deep thermocline, which seems to result from the equatorial westerly winds and the consequent propagation of downwelling equatorial/coastal Kelvin waves.
The southward displacement of the ITCZ in MAM, together with the related anomalous westward gradient of CCSM3 SLP (about $2 \mathrm{mb}$ across the tropical basin, Fig. 5c), are associated with the appearance of an intense $5 \mathrm{~m} \mathrm{~s}^{-1}$ westerly anomaly in the zonal trade winds at the surface (Fig. 4c) and an easterly anomaly at 200 $\mathrm{mb}$ (not shown). The westerly anomaly of the zonal trade winds along the equator causes the winds to change direction so that westerly winds blow along the equator in MAM as shown in Fig. 2c. These anomalous winds are indications of a greatly weakened (even reversed) Atlantic Walker cell, with the weakening most intense north of the equator. The weakened Walker cell, in turn, is reminiscent of the warm phase of the Atlantic El Niño, except that the trade wind reversal occurs in CCSM3 every year during MAM instead of every few years in JJA. As discussed in the introduction, the southeasterly trade winds that prevail throughout most of the year along the equator in the Atlantic sector are in balance with an eastward SLP gradient. In CCSM3 the $3 \mathrm{~m} \mathrm{~s}^{-1}$ westerlies that develop in MAM occur in balance with an anomalous westward SLP gradient. These westerlies force Ekman convergence and downwelling at the base of the ocean mixed layer along the equator, which in turn acts to reduce entrainment cooling of the mixed layer. The resulting warm SST bias in the eastern equatorial basin supports the westward SLP gradient and the westerly winds.

To identify the causes of errors in surface winds we first attempt to separate those resulting from errors in internal atmospheric processes from those resulting from interactions with the ocean. We isolate the errors in internal atmospheric processes by comparing CCSM3 with CAM3 in which observed SSTs are prescribed. The CAM3 wind errors in Figs. 4e, f show similar (but weaker) patterns of wind velocity bias. Along the equator the anomalous westerlies in MAM occur even in the absence of errors in SST (i.e., they appear in CAM3 as well as in CCSM3, but the strength is weaker). Examination of SLP and precipitation maps shows that the anomalous westerlies are connected with a weakened Walker circulation resulting from an imbalance in SLP along the equator (1-2-mb excess pressure over the northern Amazon) (Fig. 5). The weakening of the CAM3 Walker circulation along the equator does not occur in JJA; instead, it is slightly strengthened.

Over the off-equatorial latitudes, the excessive trade wind strength in CCSM3 and CAM3 both reflect the presence of a persistent enhancement of the subtropical high pressure systems. The centers of the subtropical high pressure systems of both CCSM3 and CAM3 are slightly shifted northward in Northern Hemisphere, 
a) Bias (Ccsm3-Obs)
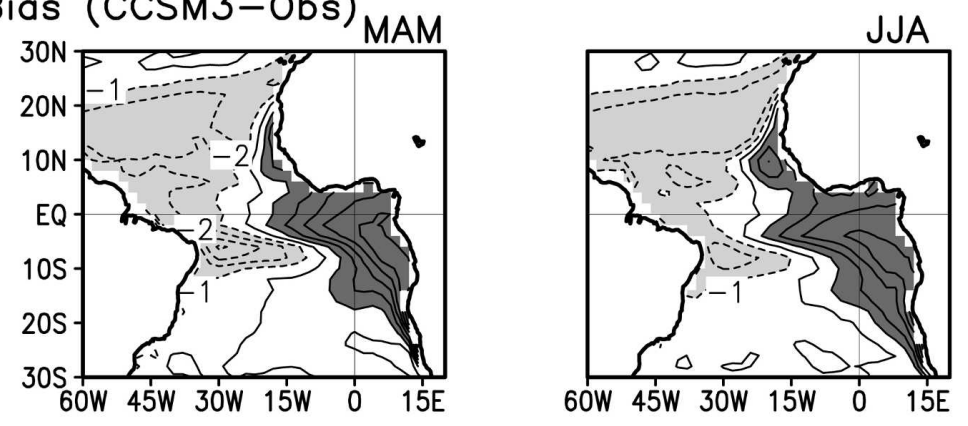

b) Depth of Thermocline (Average btw $25 \mathrm{~N}$ and $30 \mathrm{~N}$ )

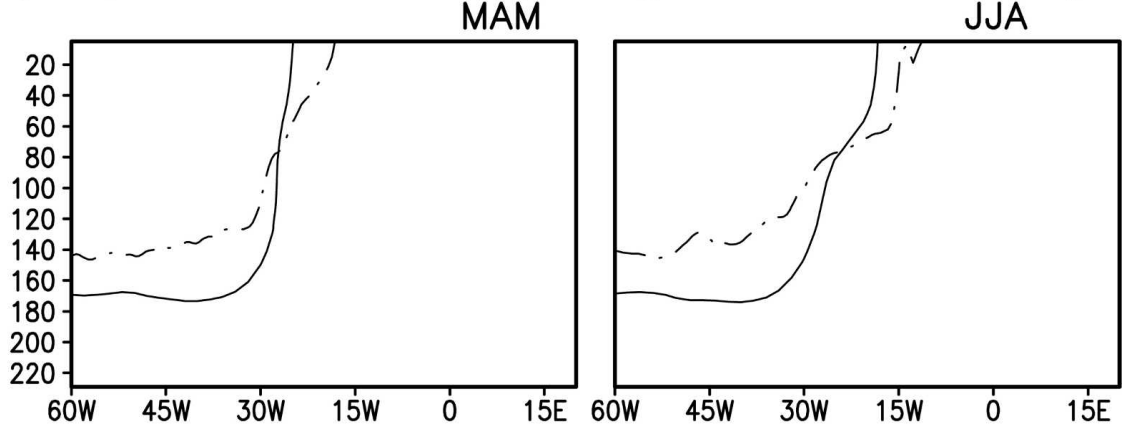

c) Depth of Thermocline (Average btw $10 \mathrm{~N}$ and $15 \mathrm{~N}$ )

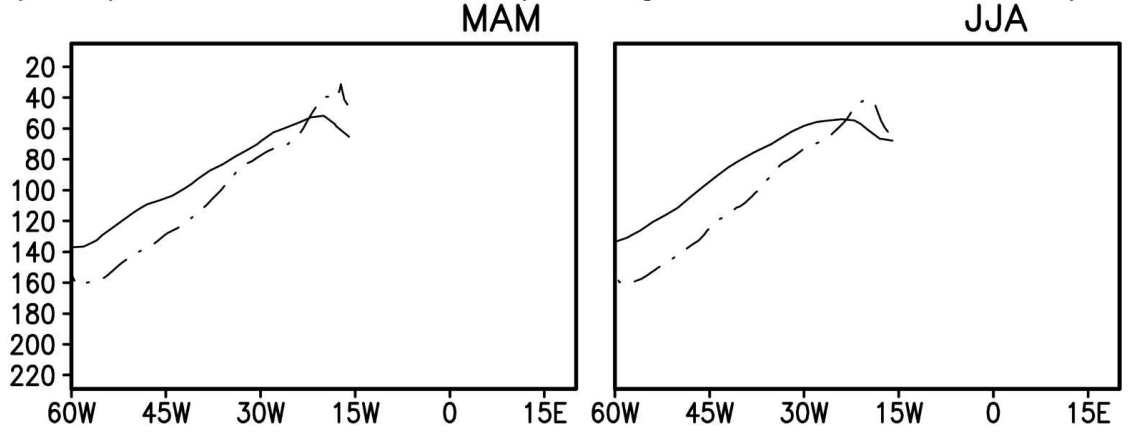

d) Depth of Thermocline (Average btw $5 S$ and EQ)

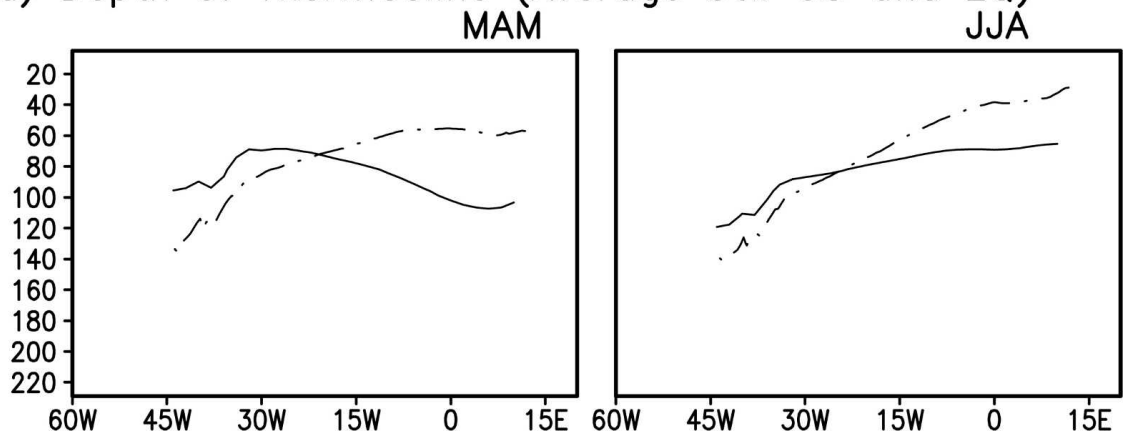

FIG. 3. Seasonal CCSM3 ocean heat content bias and depth of thermocline. (a) Bias in averaged upper-ocean temperature (averaged 5-96 m). Units: ${ }^{\circ} \mathrm{C}$. (b), (c) Depth of the thermocline (as indicated by the depth of the $20^{\circ} \mathrm{C}$ isotherm) in northern tropical Atlantic (averaged over $10^{\circ}-15^{\circ} \mathrm{N}$ ) and equatorial area (averaged over $5^{\circ} \mathrm{S}-0^{\circ} \mathrm{N}$ ) for CCSM3 (solid line) and observed (dashed line). Units: $\mathrm{m}$. 

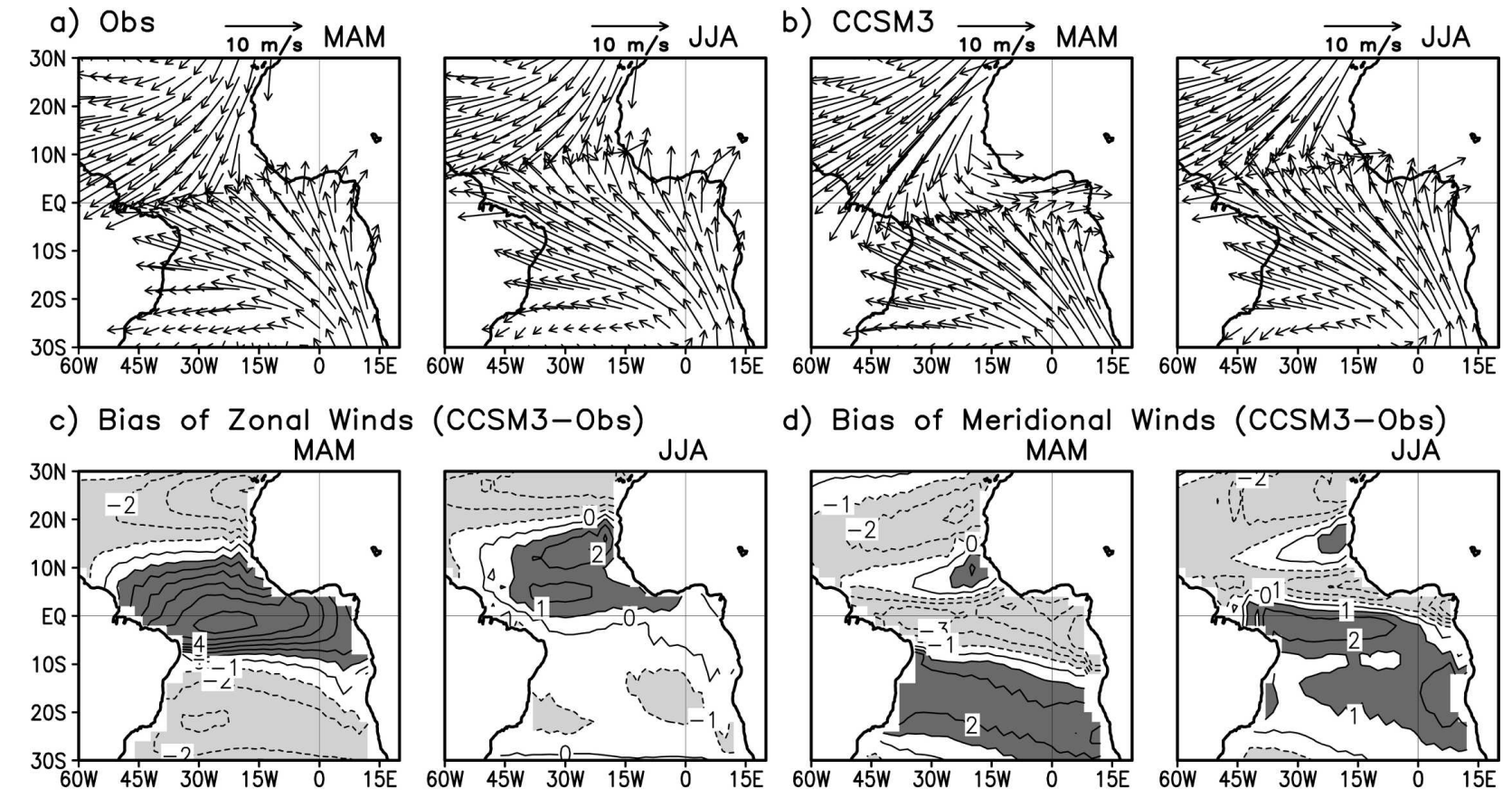

d) Bias of Meridional Winds (CCSM3-Obs)
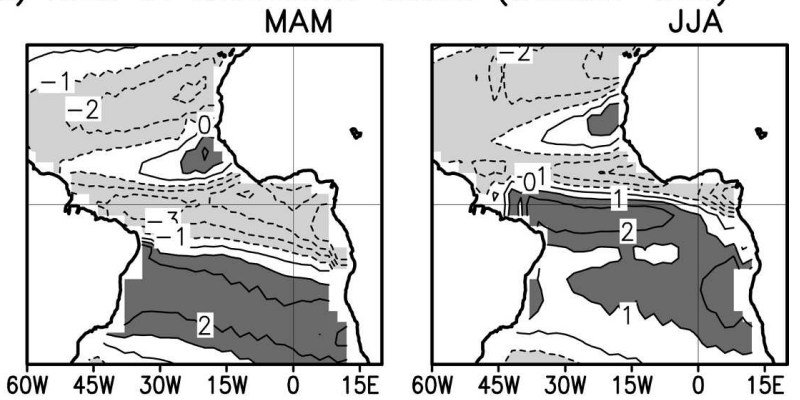

e) Bias of Zonal Winds (CAM3-Obs)
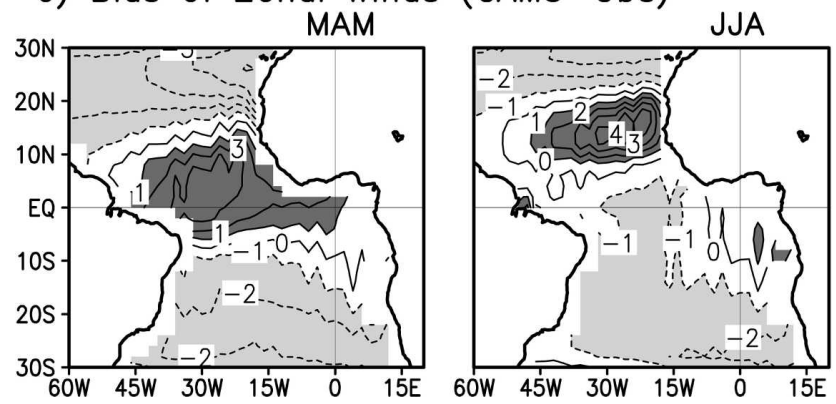

f) Bias of Meridional Winds (CAM3-Obs)

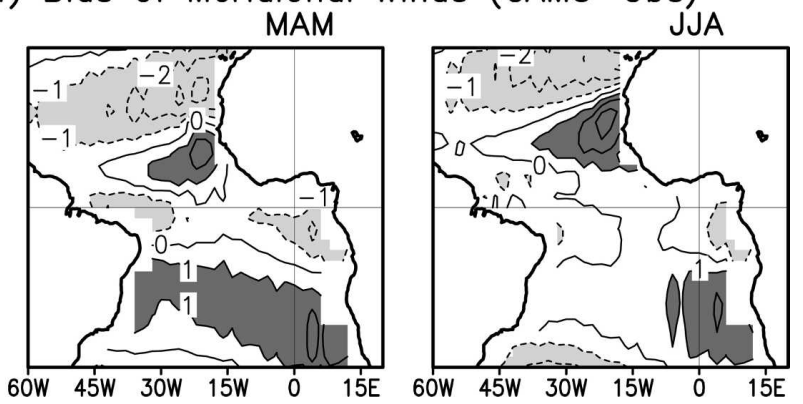

FIG. 4. Seasonal surface winds for (a) observed, (b) CCSM3, and (c) CCSM3 zonal wind bias; (d) CCSM3 meridional wind bias; (e) CAM3 zonal wind bias; and (f) CAM3 meridional wind bias. Units: $\mathrm{m} \mathrm{s}^{-1}$.

which is related to the negative bias of SLP over the West Africa coast (Figs. 5c,d). This shift causes the southerly wind bias along the West Africa coast near $10^{\circ} \mathrm{N}$, which in turn results in the SST warm bias in this area resulting from the decrease of coastal upwelling. In MAM, the CCSM3 SLP error is largest in the North Atlantic sector reaching 4-5 mb, with extensions eastward over northwest Africa and equatorward west of $40^{\circ} \mathrm{W}$ (Fig. 5). During this season there are also substantial errors in SLP in the South Atlantic. In JJA the error is largest in the North Pacific, but is still substantial in the North Atlantic.

One possible explanation for the positive bias in SLP in the subtropics is an anomalously intensified Hadley circulation. To diagnose the meridional vertical circulation we focus on the meridional section at $0^{\circ} \mathrm{E}$ in CCSM3, which transects the eastern side of the oceanic cold tongue and crosses into the African continent north of $4^{\circ} \mathrm{N}$. The vertical motion field (Fig. 6) shows that the descending motion in the subtropics is indeed too strong. In MAM the ascending motion associated with the ITCZ is substantially intensified with respect to the observed motion field, with the largest velocity errors south of the equator occurring above $500 \mathrm{mb}$. The intense convection is reflected in intense precipitation (Fig. 7) and consequent diabatic heat release. In JJA convection extends too far northward onto the northwest African continent, in addition to being too intense and extending too high in the atmosphere.

The intense surface convergence resulting from the enhanced Hadley circulation in CCSM3 increases moisture convergence. Thus, precipitation rates in the ITCZ during MAM $\left(8 \mathrm{~mm}\right.$ day $\left.^{-1}\right)$ are $30 \%$ higher than the observed values over the open ocean and are even 
a) Obs

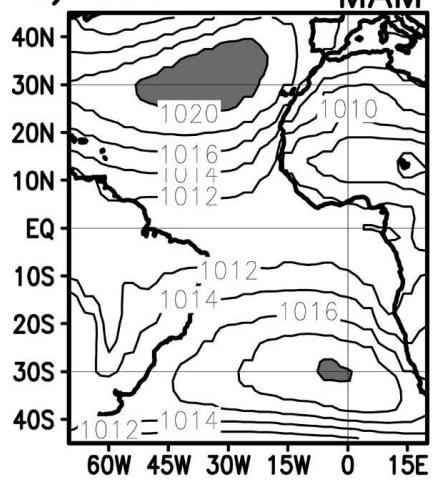

JJA b) $\operatorname{CCSM} 3$

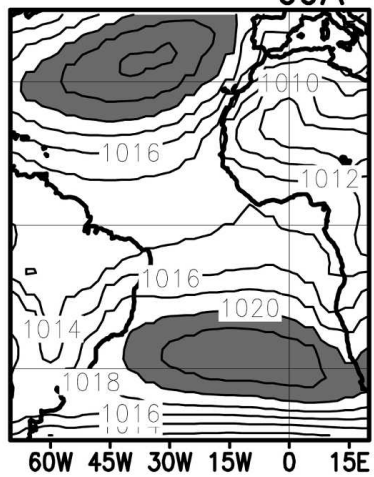

MAM

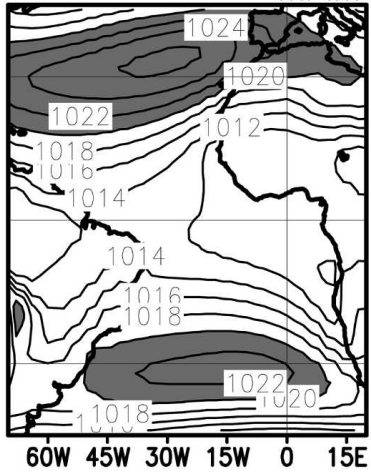

JJA

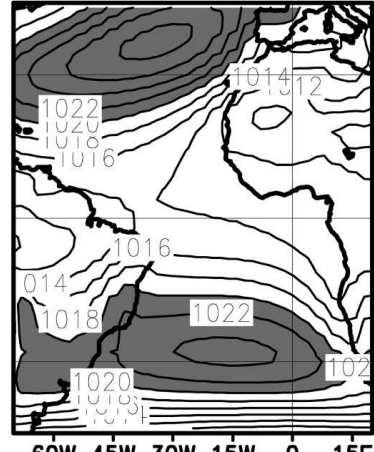

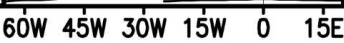

c) Bias (CCsM3-Obs)

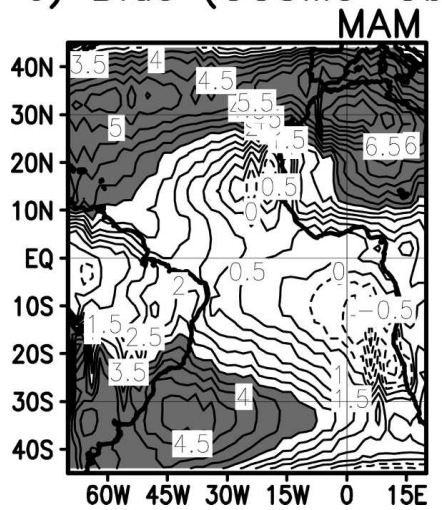
JJA

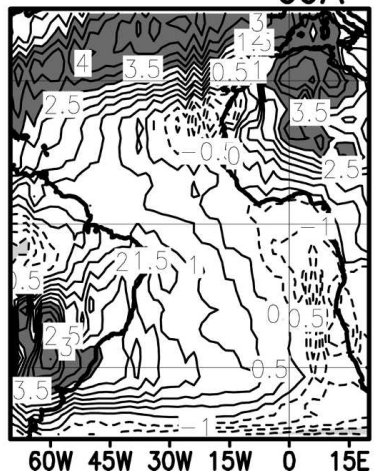

d) Bias (CAM3-Obs)

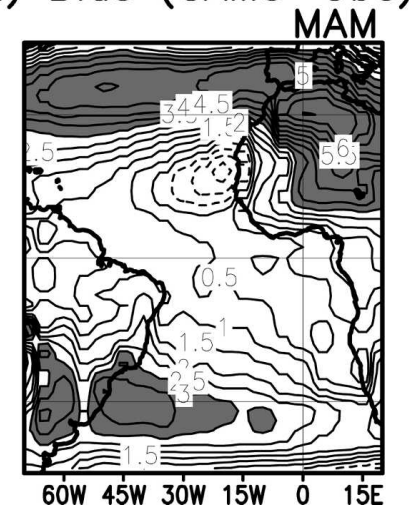

JJA

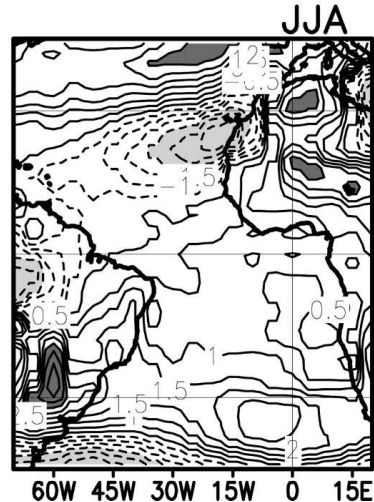

FIG. 5. Seasonal SLP for (a) observed, (b) CCSM3, (c) CCSM3 bias, and (d) CAM3 bias. Contour intervals for (a) and (b) are 2 $\mathrm{mb}$, and for (c) and (d) are $0.5 \mathrm{mb}$.

higher over Africa (Fig. 7). On the other hand, the weakened Walker cell is reflected in the presence of insufficient precipitation over the Amazon and excess precipitation over West Africa (Fig. 7). This zonal dipole pattern of precipitation bias occurs in both MAM and JJA in CCSM3 when the Walker circulation along the equator is weakened. In CAM3 this dipole pattern only occurs in MAM, but not in JJA when the Walker circulation along the equator is instead stronger (Fig. 4e). Clearly the rainfall biases at both continents bordering the tropical Atlantic are strongly associated with errors in the strength of the Walker cell.

We explore the coupled feedback between anomalous vertical motion and thus precipitation and anomalous SST by comparing precipitation in CCSM3 with CAM3 (Fig. 7). Errors in precipitation are greatly reduced in CAM3 with prescribed SST. In MAM the excess rainfall in the southeast is reduced from 5-6 to 1 $\mathrm{mm} \mathrm{day}{ }^{-1}$, indicating that much of the source of precipitation error in this region, which is related to the southward displacement of the ITCZ, is associated with coupled interactions. On the other hand, over north- west Africa, between $10^{\circ}$ and $20^{\circ} \mathrm{N}$, the rainfall is excessive in both CCSM3 and CAM3 and is produced by anomalously deep convection that is not capped by descending flow aloft as it should be (Fig. 6). The similarity of the errors in precipitation and SLP suggest that the causes should be traced back to the atmospheric models. A consequence of the additional soil moisture and cloud shading resulting from excess precipitation is colder surface air temperature in this region than that observed (not shown), suggesting that the land surface model may play an important role as well.

North of the seasonal position of the ITCZ $\left(\sim 7^{\circ} \mathrm{N}\right)$ solar radiation in CCSM3 is reduced throughout the year by as much as $60 \mathrm{~W} \mathrm{~m}^{-2}$ compared to that of the observations (Fig. 8). But, the enhanced total cloud cover (not shown) is not associated with enhanced precipitation. The northeast trade winds are more intense north of $10^{\circ} \mathrm{N}$ (Fig. 4), with enhanced upwelling to the north of the observed ITCZ and enhanced downwelling to the south (Fig. 9). In the region of enhanced upwelling the thermocline is elevated by $10 \mathrm{~m}$ (Fig. 3b) and entrainment cooling is enhanced. This effect, to- 

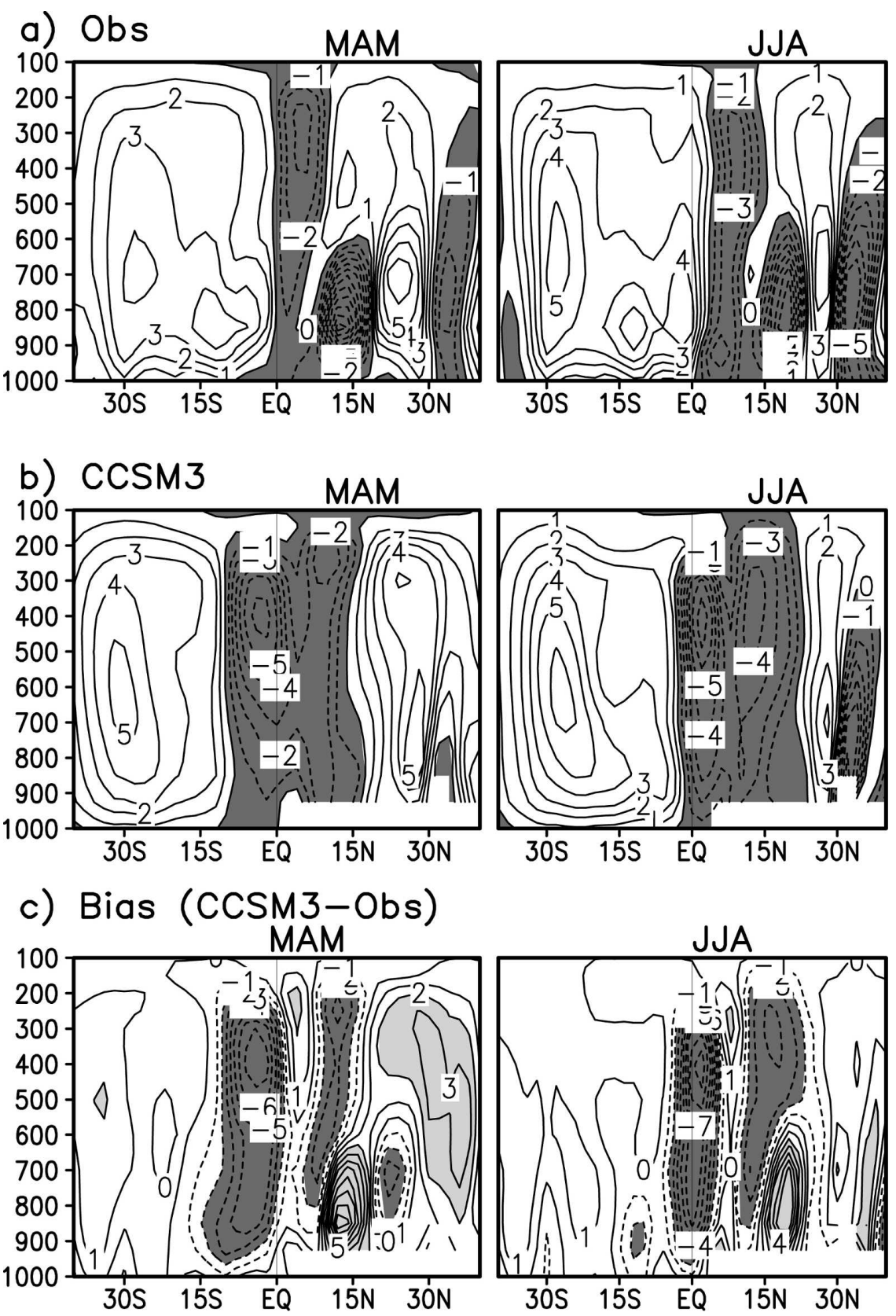

FIG. 6. Seasonal atmospheric vertical velocity (omega) with latitude and height along $0^{\circ} \mathrm{E}$; descending (light shaded) and ascending (dark shaded) motion. Contour interval is $0.01 \mathrm{~Pa} \mathrm{~s}^{-1}$ for (a) observed, (b) CCSM3, and (c) CCSM3 bias.

gether with the reduction in solar radiation and enhanced wind-induced thermodynamic surface fluxes, is responsible for a $1^{\circ}-2^{\circ} \mathrm{C}$ anomalous cooling of SST in this region. North of $20^{\circ} \mathrm{N}$ CCSM3 has stronger downwelling, resulting in deeper thermocline and warmer heat content, while SST has warm bias in MAM and cold bias in JJA, implying that wind-induced surface fluxes are more important. Very close to the coast of northwest Africa the trade winds weaken, reducing the upwelling that normally predominates in boreal summer.

CAM3 shortwave radiation has a very similar bias pattern and strength to CCSM3 in the northern Tropics, but differs in strength in the southern Tropics. CAM3 has errors in simulating net surface shortwave radiation resulting from errors in total cloud cover (not 
a) Obs

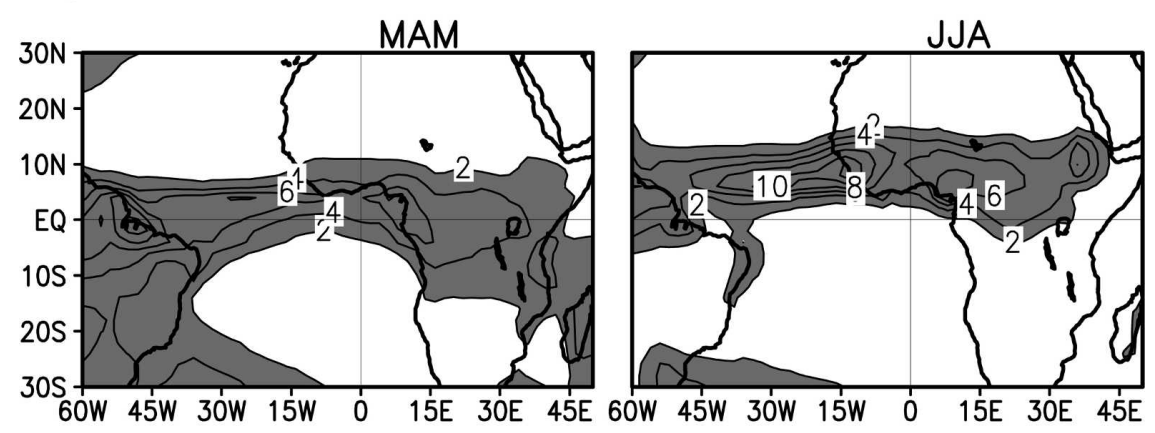

b) $\operatorname{ccs} 33$

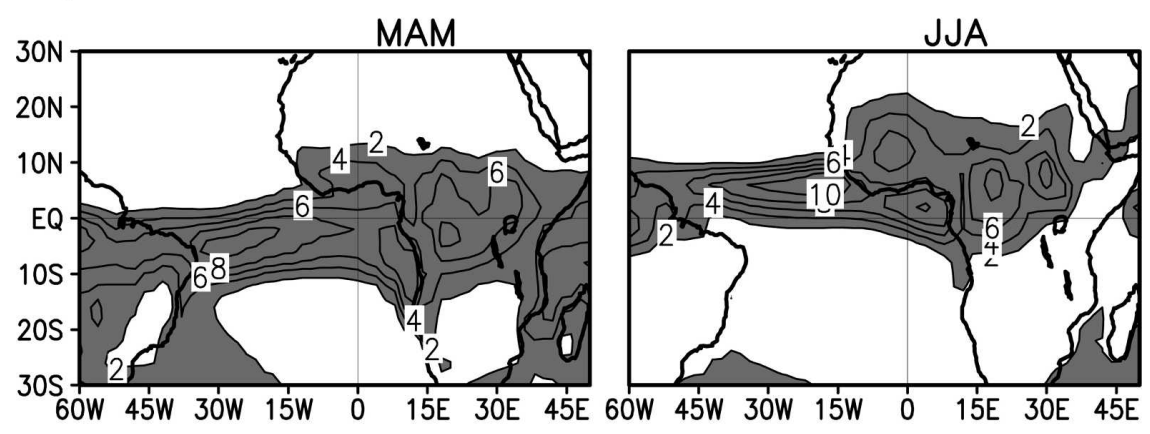

c) Bias (Ccsm3-Obs)

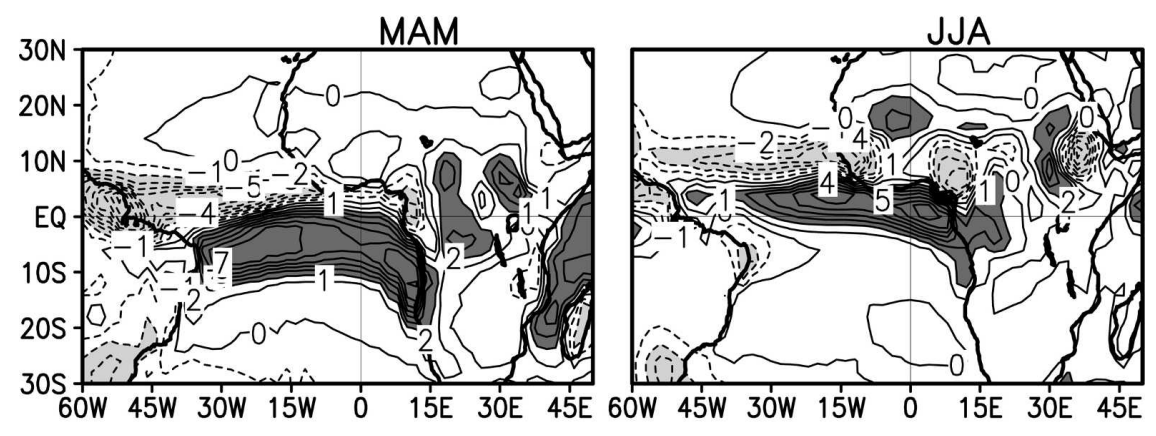

d) Bias (CAM3-Obs)

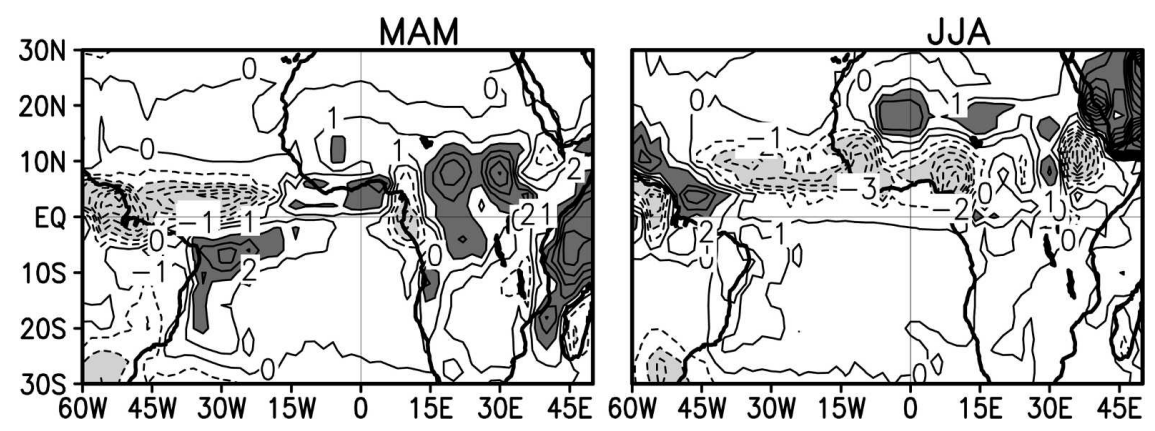

FIG. 7. Seasonal precipitation: (a) observed, (b) CCSM3, (c) CCSM3 bias, and (d) CAM3 bias. Units: $\mathrm{mm} \mathrm{day}^{-1}$. 
a) Obs

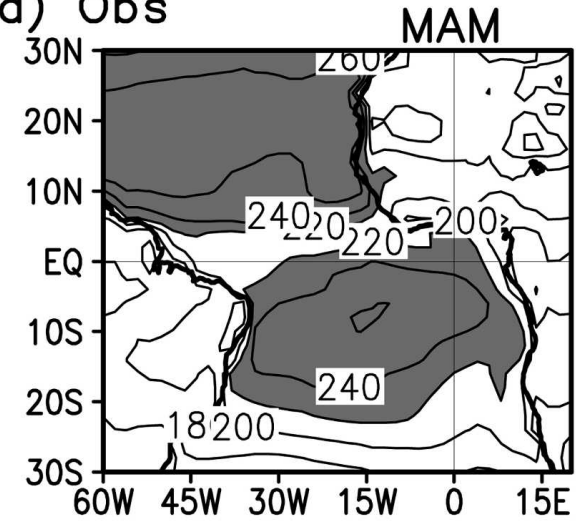

b) Bias (CCSM3-Obs)

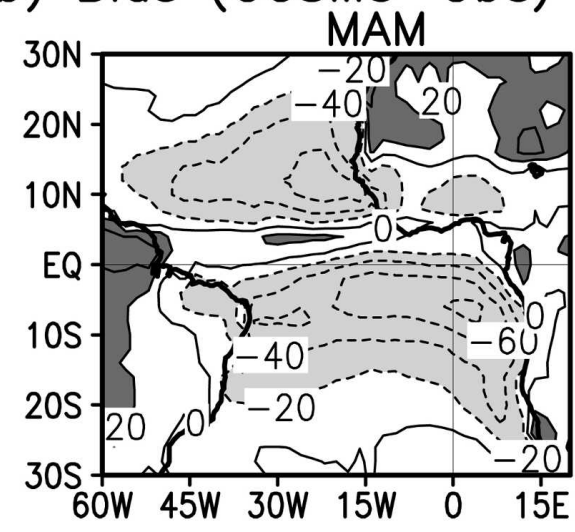

c) Bias (CAM3-Obs)

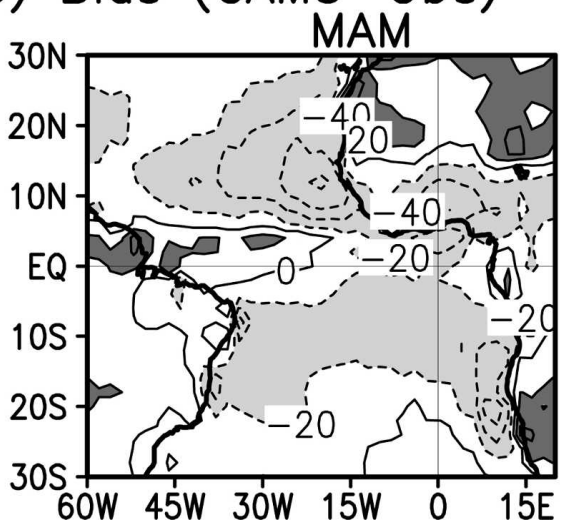

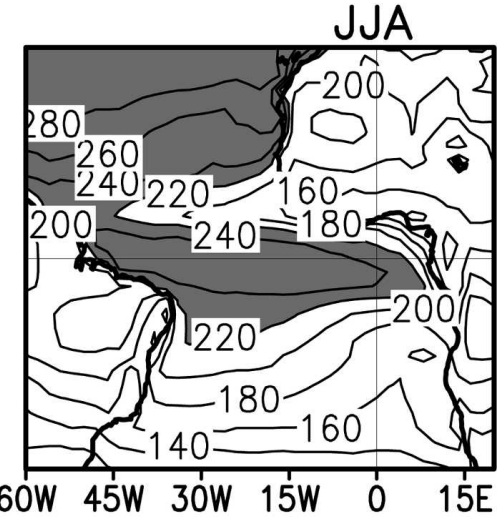
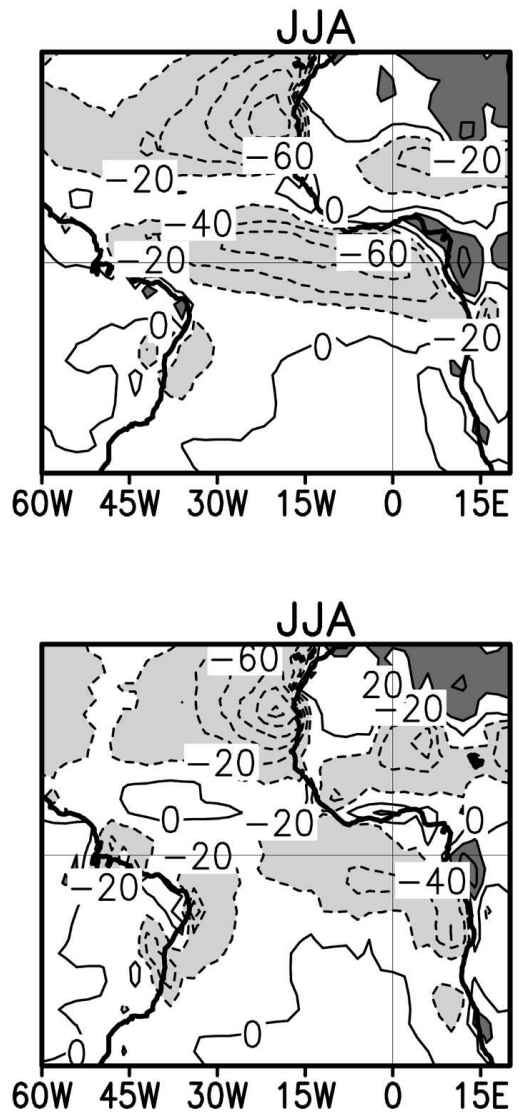

FIG. 8. Seasonal surface radiative fluxes: (a) observed net short wave radiation, (b) CCSM3 net shortwave radiation bias, and (c) CAM3 net shortwave radiation bias. Contour intervals: $20 \mathrm{~W} \mathrm{~m}^{-2}$.

shown), which in turn may be due to the enhanced Hadley circulation. The deficiency of solar radiation may contribute to the cold SST bias. In CCSM3, close to the equator in the Gulf of Guinea, net surface solar radiation is also too low by as much as $60 \mathrm{~W} \mathrm{~m}^{-2}$ because of excessive clouds. However, the absence of solar radiation does not lead to cooling, suggesting that other terms in the mixed layer heat budget have been altered to compensate. Observational estimates suggest that entrainment/mixing should remove $50-100 \mathrm{~W} \mathrm{~m}^{-2}$ from the mixed layer during JJA (Foltz et al. 2003). South of $10^{\circ} \mathrm{S}$ along the coast of Africa solar radiation is close to its observed value, while we have already seen that the upwelling-favorable winds are enhanced. 


\section{a) Obs}

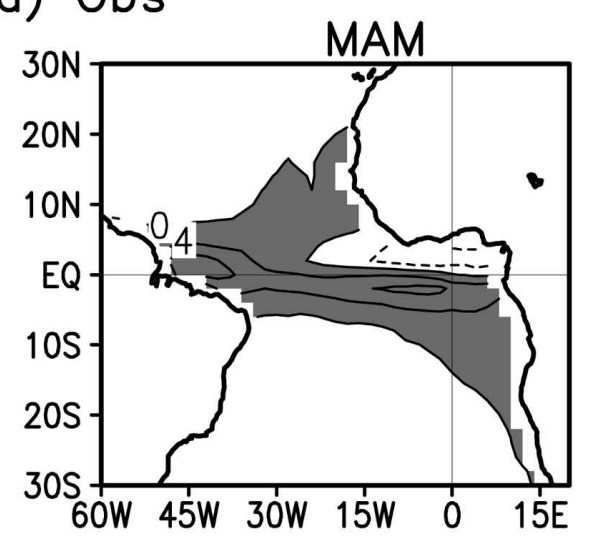

b) $\operatorname{ccs} 33$

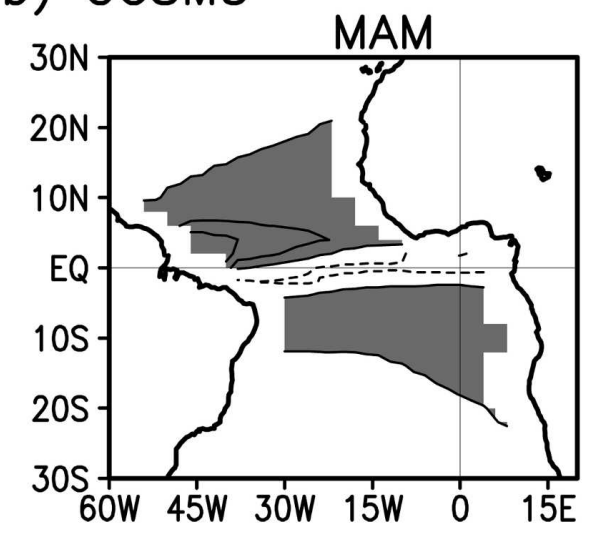

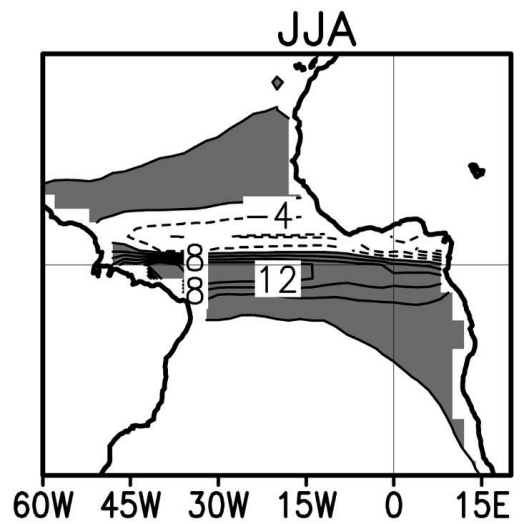

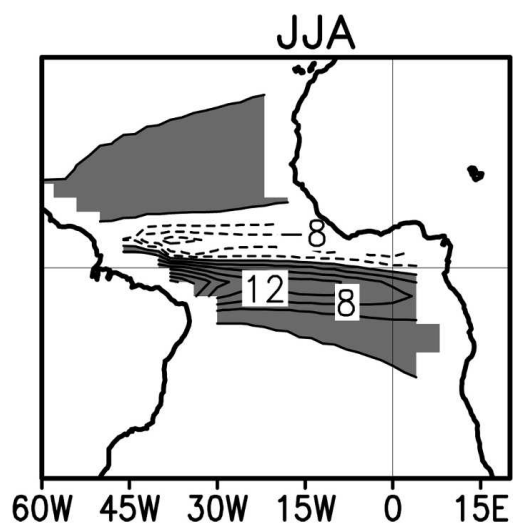

c) Bias (CCSM3-Obs)
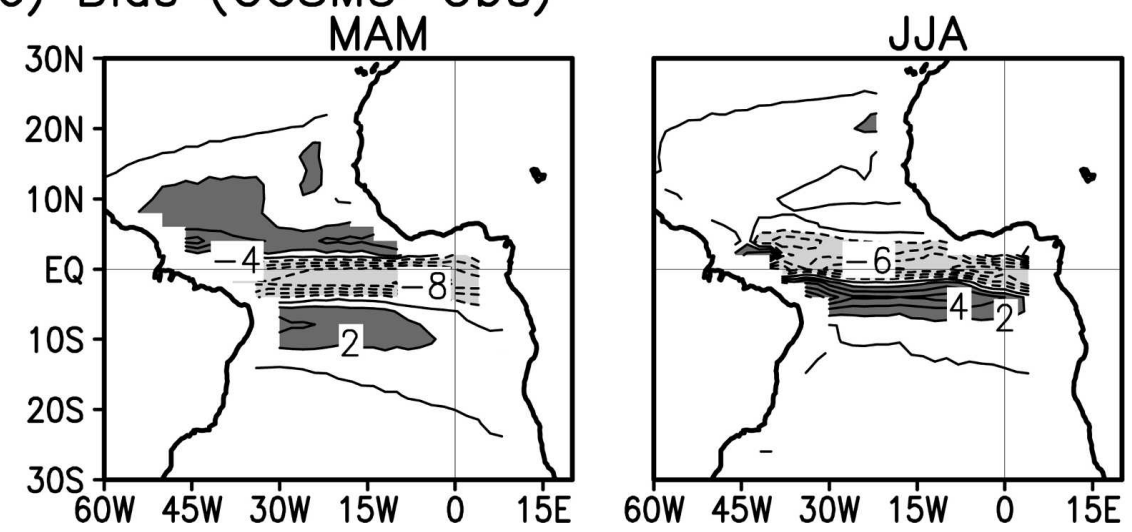

FIG. 9. Seasonal Ekman vertical velocity: (a) observed, (b) CCSM3, and (c) CCSM3 bias. Contour intervals: $2 \times 10^{-6} \mathrm{~m} \mathrm{~s}^{-1}$.

However, here the reduction in entrainment resulting from the anomalous deepening of the thermocline leads to an elevation of SST by several degrees.

To evaluate the role of mixed layer entrainment/ mixing in CCSM3 we need to examine the ocean stratification. Along the equator, the observed thermocline slopes upward from a depth of $80 \mathrm{~m}$ at $30^{\circ} \mathrm{W}$ to $50 \mathrm{~m}$ at $0^{\circ} \mathrm{W}$ during MAM (Fig. 3c) to balance the easterly surface stress. The weakening of the Walker cell and the reversal of the trade winds causes the CCSM3 thermocline to reverse this slope, descending from $70-\mathrm{m}$ depth at $30^{\circ} \mathrm{W}$ to $100-\mathrm{m}$ depth at $0^{\circ} \mathrm{W}$. The reversal of the zonal trade winds also reverses the sign of the vertical velocity at the base of the oceanic mixed layer 


\section{Climatological Equatorial Zonal Current (Average btw $2 \mathrm{~S}$ and $2 \mathrm{~N}$ ) Obs MAM}
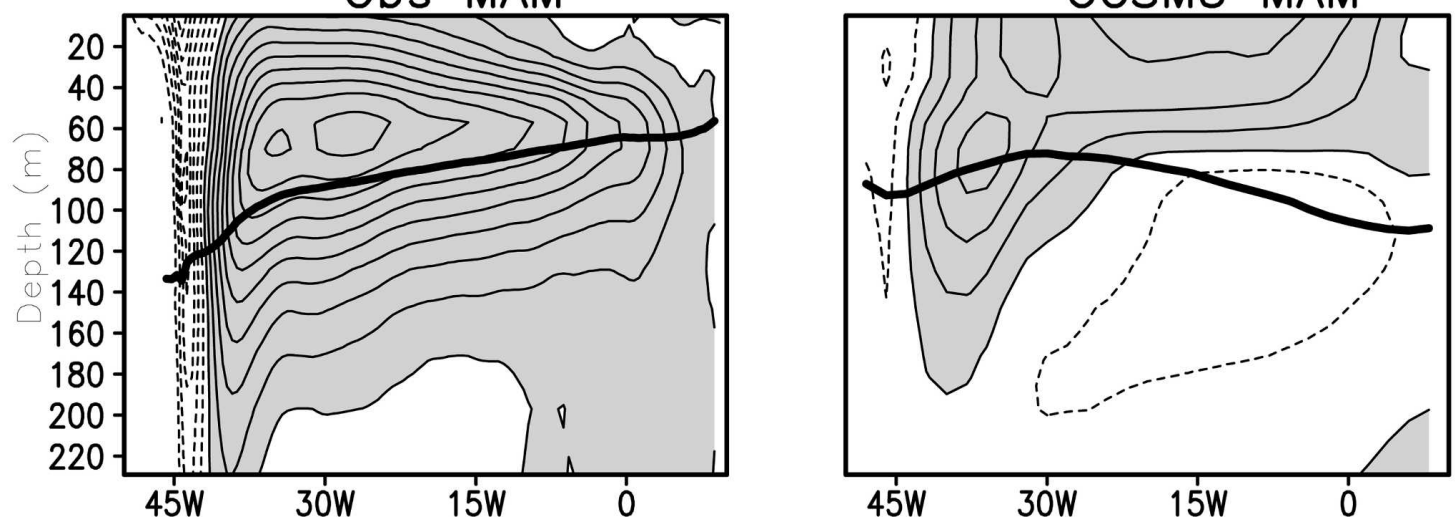

FIG. 10. Zonal current averaged $2^{\circ} \mathrm{S}-2^{\circ} \mathrm{N}$ during MAM. Depth of the $20^{\circ} \mathrm{C}$ isotherm is superimposed in gray: (left) observed and (right) CCSM3. Contour intervals: $20 \mathrm{~cm} \mathrm{~s}^{-1}$.

(Fig. 9). In JJA, the spatial pattern of Ekman pumping is similar to that observed, but is shifted southward, reflecting anomalous southward shift of the ITCZ (Fig. 7).

The heat content of the upper ocean, thus, is anomalously high on the southeast side of the basin and anomalously low on the northeast side (a pattern closely matching the bias in SST except near the equator in MAM) by up to $4^{\circ} \mathrm{C}$ averaged over the depth range of 5-96 m (Fig. 3a). Along the equator the observed westward upper-ocean pressure gradient (reflecting the slope of sea level) is weakest in MarchApril. During these months the bias in the zonal gradient of heat content, also reflected in the depth of the thermocline, is sufficient to cause the ocean surface pressure gradient to reverse. The result of the reversal of both the winds and pressure gradient causes the acceleration of an eastward jet with speeds exceeding 40 $\mathrm{cm} \mathrm{s}^{-1}$ at the surface and reaching depths of $80 \mathrm{~m}$. Below this jet a weak westward Equatorial Undercurrent develops with speeds of $20 \mathrm{~cm} \mathrm{~s}^{-1}$ (Fig. 10). This balance of terms contrasts with the observed circulation in which a brief interval of eastward currents along the equator at $23^{\circ} \mathrm{W}$ may result from a surfacing of the eastward Equatorial Undercurrent (Grodsky et al. 2005). The CCSM3 thermocline is also more stratified than observed and thus the ocean is too cold at lower thermocline depths. The absence of cooling resulting from entrainment/mixing is why SST in the Gulf of Guinea is warmer than that observed despite the reduced solar radiation.

\section{Conclusions}

CCSM3 represents a substantial advance in coupled climate modeling. The extensive sets of experiments that have been made available provide a unique opportunity to address aspects of coupled climate. But, CCSM3 shares with many coupled models substantial biases in the tropical Atlantic sector, which are more prominent than in the other tropical sectors (other examples are presented in Davey et al. 2002). In Fig. 11, for example, the similarity between the SST bias in CCSM3 and in the National Centers for Environmental Prediction Climate Forecast System (CFS) coupled climate model is striking despite great differences in the model parameterizations.

Several recent studies have addressed aspects of the tropical bias and have suggested a variety of potential causes, including deficient low-level clouds, problems with the West African monsoon, or inadequate eastern coastal upwelling ( $\mathrm{Yu}$ and Mechoso 1999; Deser et al. 2006; Large and Danabasoglu 2006). In this paper we present a diagnostic study focusing on bias in the tropical Atlantic sector and present some alternative ideas to explain the sources of bias in CCSM3. We believe these ideas may also explain why similar patterns of bias develop in other coupled models, such as CFS, despite wide differences in model physics and numerics.

The most striking feature in the bias of SST is the presence of anomalously warm SSTs to the southeast of the climatological position of the ITCZ and anomalously cool SSTs to the north. This SST dipole occurs in conjunction with a southward displacement of the ITCZ by $5^{\circ}-10^{\circ}$, crossing south of the equator in MAM. The anomalous southward shift of the ITCZ is associated with a southward shift of precipitation as well as the appearance of northerly wind errors on the equator, which act to enhance the cooling of northern SSTs. In fact, each of these features of the bias in CCSM3 is also associated with the observed interhemispheric mode 


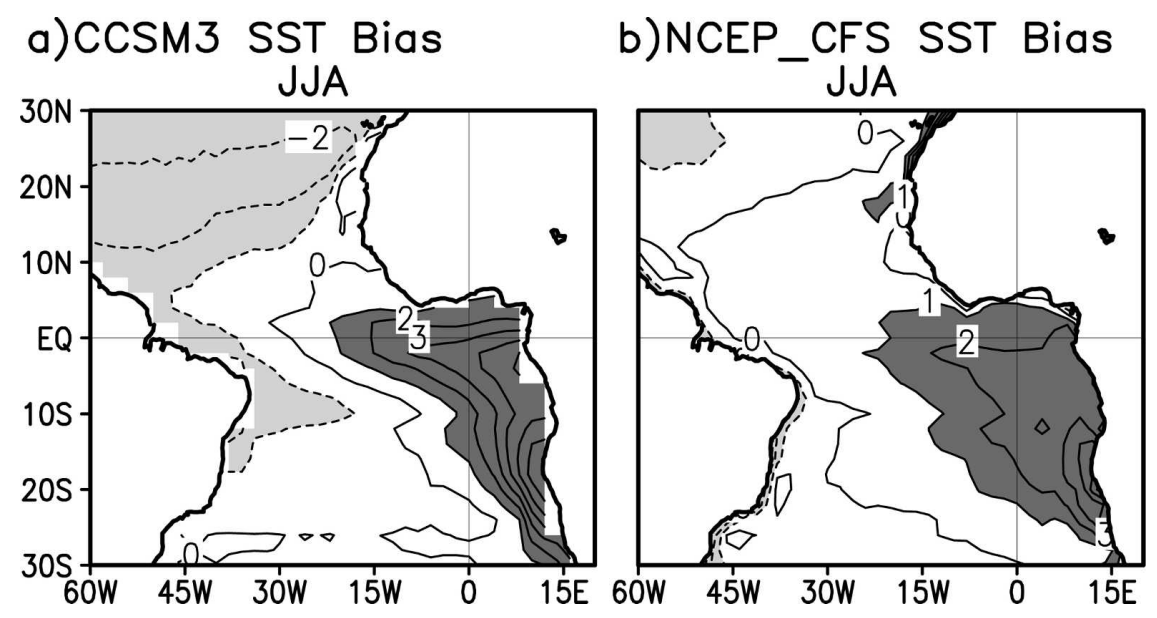

FIG. 11. SST bias of (a) CCSM3 and (b) NCEP CFS (see Saha et al. 2005 for model details). Contour intervals: $1^{\circ} \mathrm{C}$.

(also known in the literature as the "dipole mode"). The interhemispheric mode is seasonal, with the greatest amplitude in MAM, and is observed to vary on decadal time scales. Studies of its dynamics indicate that it is the result of both local air-sea interaction and remote forcing tied to ENSO (Ruiz-Barradas et al. 2003). In CCSM3 it seems that errors in the coupled model project onto the physics of the interhemispheric mode, which then act to reinforce themselves through coupled air-sea interactions (see Fig. 11). The Hadley circulation in CCSM3 is also enhanced, thus giving rise to stronger trade winds in both hemispheres. The latter factor may explain why the CCSM3 wind biases in both hemispheres have the same phase.

Along the equator the CCSM3 winds are characterized by intense westerlies in MAM. These anomalous westerlies occur in conjunction with a modest eastward anomalous gradient of SST and a dramatic deepening of the equatorial thermocline in the eastern basin. These features, as well, are associated with aspects of the normal year-to-year variability of the tropical Atlantic, known as the Atlantic El Niño. The warm water accumulated in the eastern basin resulting from the seasonal equatorial westerly winds then flows southward along the Africa coast, resulting in anomalous warming along the southwest African coast and the deepening of the thermocline in this region. The consequent SST bias is reminiscent of the observed phenomenon known as the Benguela Niño. Like the interhemispheric mode, the Atlantic El Niño is quite seasonal, occurring in boreal summer when the cold tongue of water normally surfaces along the equator in the east. Here, by comparing the evolution of the anomalous trade winds in CCSM3 and the corresponding atmospheric simulation using observed climatological SST, we are able to iden- tify sources for the boreal spring anomalous Atlantic El Niño in CCSM3. One source is the development of an anomalous westward gradient in SLP along the equator, which is potentially related to the deficiency of the Amazonian precipitation. The resulting westerly wind anomalies are then reinforced by air-sea interactions leading to excess warming of the eastern ocean mixed layer and consequent enhancement of the westward gradient of equatorial SLP. A second potential mechanism involves the influence of the excessively intense subtropical SLP anomalies on the SLP of the western tropical Atlantic.

Biases are also evident in the vertical structure of convection. In addition to the ITCZ being displaced southward, convection is greatly enhanced and extends to greater altitudes. The enhancement of convection at low latitudes is balanced by more intense descending motion in the subtropics. The excessive precipitation is highly related to the elevated SST in the southeastern basin. Over northwest Africa anomalously high cloud cover resulting from the strengthened ascending motion reduces solar radiation by $10-20 \mathrm{~W} \mathrm{~m}^{-2}$, while the excessive precipitation extends northward into the southern Sahara, broadening the range of latitudes in which convection is occurring and enhancing evaporative cooling. Thus, surface air temperature remains somewhat lower than that observed. This bias occurs in both CCSM3 and in the CAM3 atmospheric model, indicating that the cause of at least part of the problem may be attributable to the combined atmosphere-land model rather than a result of interactions with the ocean.

CAM3 shares with CCSM3 similar patterns (but with less intensity) of biases of SLP, winds, and shortwave radiation. Interestingly, some similar biases have also 
been found in other atmospheric general circulation models (AGCMs). Okumura and Xie (2004) showed equatorial westerlies over the eastern half of the basin in winter and spring and excessive rainfall in central Africa in the same seasons in the Center for Climate System Research (CCSR)/National Institute for Environmental Studies (NIES) AGCM. They argued that the problem of equatorial westerly wind bias may partly explain why many coupled GCMs fail to simulate the Atlantic cold tongue. As shown in our study, equatorial westerlies deepen the thermocline in the southeastern basin, thus preventing the formation of the cold tongue. The equatorial westerly is also related to the southern displacement of ITCZ during MAM in CAM3. Biasutti et al. (2006) shows that many AGCMs have anomalously abundant precipitation in the Southern Hemisphere during boreal spring, while Biasutti et al. (2005) explores the connection between terrestrial insolation and the marine precipitation. Thus, the southward displacement of ITCZ, equatorial westerlies, and West African rainfall form a coupled problem. Improved simulation of any of these factors should reduce the biases in the other factors.

In this study we have limited ourselves to examination of the simulations using unmodified physics. Greater exploration of possible mechanisms giving rise to model bias will require model experiments in which various state variables such as subtropical surface pressure have been modified. Carrying out a suite of such experiments is our next goal.

Acknowledgments. We are grateful to the NCAR Community Climate System for providing the basic model simulations and to the Program for Climate Model Diagnosis and Intercomparison for collecting and archiving the model data, the JSC/CLIVAR Working Group on Coupled Modelling (WGCM) and their Coupled Model Intercomparison Project (CMIP), the Climate Simulation Panel for organizing the model data analysis activity, and the IPCC WG1 TSU for technical support. The IPCC Data Archive at Lawrence Livermore National Laboratory is supported by the Office of Science, U.S. Department of Energy. We gratefully acknowledge support from the NASA Oceans Program and NOAA's Office of Global Programs. QuikSCAT wind is provided by the Seaflux data system at NASA JPL.

\section{REFERENCES}

Adler, R. F., and Coauthors, 2003: The version-2 Global Precipitation Climatology Project (GPCP) monthly precipitation analysis (1979-present). J. Hydrometeor., 4, 1147-1167.

Atlas, R., R. N. Hoffman, S. C. Bloom, J. C. Jusem, and J. Ard- izzone, 1996: A multiyear global surface wind velocity dataset using SSM/I wind observations. Bull. Amer. Meteor. Soc., 77, 869-882.

Biasutti, M., D. S. Battisti, and E. S. Sarachik, 2005: Terrestrial influence on the annual cycle of the Atlantic ITCZ. J. Climate, 18, 211-228.

-, A. Sobel, and Y. Kushnir, 2006: AGCM precipitation biases in the tropical Atlantic. J. Climate, 19, 935-958.

Boville, B. A., and P. R. Gent, 1998: The NCAR Climate System Model, version one. J. Climate, 11, 1115-1130.

Carlson, T. N., and S. G. Benjamin, 1980: Radiative heating rates for Saharan dust. J. Atmos. Sci., 37, 193-213.

Chang, P., and G. Philander, 1994: A coupled ocean-atmosphere instability of relevance to the seasonal cycle. J. Atmos. Sci., 51, 3627-3648

Chiang, J. C. H., Y. Kushnir, and A. Giannini, 2002: Deconstructing Atlantic Intertropical Convergence Zone variability: Influence of the local cross-equatorial sea surface temperature gradient and remote forcing from the eastern equatorial $\mathrm{Pa}-$ cific. J. Geophys. Res., 107, 4004, doi:10.1029/2000JD000307.

—, M. Biasutti, and D. S. Battisti, 2003: Sensitivity of the Atlantic Intertropical Convergence Zone to Last Glacial Maximum boundary conditions. Paleoceanography, 18, 1094, doi:10.1029/2003PA000916.

Collins, W. D., and Coauthors, 2006a: The Community Climate System Model version 3 (CCSM3). J. Climate, 19, 2122-2143.

- and Coauthors, 2006b: The formulation and atmospheric simulation of the Community Atmosphere Model version 3 (CAM3). J. Climate, 19, 2144-2161.

Danabasoglu, G., and Coauthors, 2006: Diurnal coupling in the tropical oceans of CCSM3. J. Climate, 19, 2347-2365.

Davey, M., and Coauthors, 2002: STOIC: A study of coupled model climatology and variability in tropical ocean regions. Climate Dyn., 18, 403-420.

Deser, C., A. Capotondi, R. Saravanan, and A. Phillips, 2006: Tropical Pacific and Atlantic climate variability in CCSM3. J. Climate, 19, 2451-2481.

DeWitt, D. G., 2005: Diagnosis of the tropical Atlantic nearequatorial SST bias in a directly coupled atmosphere-ocean general circulation model. Geophys. Res. Lett., 32, L01703, doi:10.1029/2004GL021707.

Foltz, G. R., S. A. Grodsky, J. A. Carton, and M. J. McPhaden, 2003: Seasonal mixed layer heat budget of the tropical Atlantic Ocean. J. Geophys. Res., 108, 3146, doi:10.1029/ 2002JC001584

Graf, J., C. Sasaki, C. Winn, W. T. Liu, W. Tsai, M. Freilich, and D. Long, 1998: NASA Scatterometer Experiment. Acta Astronaut., 43, 397-407.

Grodsky, S. A., J. A. Carton, C. Provost, J. Servain, J. A. Lorenzzetti, and M. J. McPhaden, 2005: Tropical instability waves at $0^{\circ} \mathrm{N}, 23^{\circ} \mathrm{W}$ in the Atlantic: A case study using Pilot Research Moored Array in the Tropical Atlantic (PIRATA) mooring data. J. Geophys. Res., 110, C08010, doi:10.1029/ 2005JC002941.

Hagen, E., R. Feistel, J. J. Agenbag, and T. Ohde, 2001: Seasonal and interannual changes in intense Benguela upwelling (1982-1999). Oceanol. Acta, 24, 557-567.

Hazeleger, W., and R. J. Haarsma, 2005: Sensitivity of tropical Atlantic climate to mixing in a coupled ocean-atmosphere model. Climate Dyn., 25, 387-399. 
Kalnay, E., and Coauthors, 1996: The NCEP/NCAR 40-Year Reanalysis Project. Bull. Amer. Meteor. Soc., 77, 437-471.

Kushnir, Y., R. Seager, J. Miller, and J. C. H. Chiang, 2002: A simple coupled model of tropical Atlantic decadal climate variability. Geophys. Res. Lett., 29, 2133, doi:10.1029/ 2002 GL015874.

Large, W. G., and G. Danabasoglu, 2006: Attribution and impacts of upper-ocean biases in CCSM3. J. Climate, 19, 2325-2346.

Li, T., and S. G. H. Philander, 1996: On the annual cycle of the eastern equatorial Pacific. J. Climate, 9, 2986-2998.

Mitchell, T. P., and J. M. Wallace, 1992: The annual cycle in equatorial convection and sea surface temperature. J. Climate, 5, $1140-1156$.

Nigam, S., and Y. Chao, 1996: Evolution dynamics of tropical ocean-atmosphere annual cycle variability. J. Climate, 9, $3187-3205$

Okumura, Y., and S.-P. Xie, 2004: Interaction of the Atlantic equatorial cold tongue and the African Monsoon. J. Climate, 17, 3589-3602.

Pinker, R. T., I. Laszlo, and B. Zhang, 2001: Pathfinder large scale radiative fluxes: Data availability and their use in climate research. IRS 2000: Current Problems in Atmospheric Radiation, W. L. Smith and Yu. M. Timofeyev, Eds., A. Deepak Publishing, 485-488.
Rayner, N. A., D. E. Parker, E. B. Horton, C. K. Folland, L. V. Alexander, D. P. Powell, E. C. Kent, and A. Kaplan, 2003: Global analyses of sea surface temperature, sea ice, and night marine air temperature since the late nineteenth century. $J$. Geophys. Res., 108, 4407, doi:10.1029/2002JD002670.

Reynolds, R., N. Rayner, T. Smith, D. Stokes, and W. Wang, 2002: An improved in situ and satellite SST analysis for climate. $J$. Climate, 15, 1609-1625.

Ruiz-Barradas, A., J. A. Carton, and S. Nigam, 2003: Role of the atmosphere in climate variability of the tropical Atlantic. $J$. Climate, 16, 2052-2065.

Saha, S., and Coauthors, 2006: The NCEP Climate Forecast System. J. Climate, 19, 3483-3517.

Xie, S.-P., 1994: On the genesis of the equatorial annual cycle. $J$. Climate, 7, 2008-2013.

_, and J. A. Carton, 2004: Tropical Atlantic variability: Patterns, mechanisms, and impacts. Earth's Climate: The OceanAtmosphere Interaction, Geophys. Monogr., Vol. 147, Amer. Geophys. Union, 121-142.

Yu, J.-Y., and C. R. Mechoso, 1999: A discussion on the errors in the surface heat fluxes simulated by a coupled GCM. J. Climate, 12, 416-426. 
Copyright of Journal of Climate is the property of American Meteorological Society and its content may not be copied or emailed to multiple sites or posted to a listserv without the copyright holder's express written permission. However, users may print, download, or email articles for individual use. 